Portland State University

PDXScholar

\title{
Grandmothers Laughing: Intergenerational \\ Transmission of Cultural Beliefs About Pregnancy and Childbirth Among Native American Women
}

Claudia Robin Long

Portland State University

Follow this and additional works at: https://pdxscholar.library.pdx.edu/open_access_etds

Digitalrt of the Family, Life Course, and Society Commons, Gender and Sexuality Commons, and the Social Premnoensmons

Newtorks know how access to this document benefits you. Logo

\section{Recommended Citation}

Long, Claudia Robin, "Grandmothers Laughing: Intergenerational Transmission of Cultural Beliefs About Pregnancy and Childbirth Among Native American Women" (1997). Dissertations and Theses. Paper 5766.

https://doi.org/10.15760/etd.7637

This Dissertation is brought to you for free and open access. It has been accepted for inclusion in Dissertations and Theses by an authorized administrator of PDXScholar. Please contact us if we can make this document more accessible: pdxscholar@pdx.edu. 
GRANDMOTHERS LAUGHING:

INTERGENERATIONAL TRANSMISSION OF

CULTURAL BELIEFS ABOUT PREGNANCY

AND CHILDBIRTH AMONG NATIVE AMERICAN WOMEN

by

CLAUDIA ROBIN LONG

A dissertation submitted in partial fulfillment of the requirements for the degree of

DOCTOR OF PHILOSOPHY

in

SOCIAL WORK AND SOCIAL RESEARCH

Portland State University

(C) 1997 


\section{DISSERTATION APPROVAI}

The abstract and dissertation of Claudia Robin Long for the Doctor of Philosophy in Social Work and Social Research were presented July 14, 1997, and accepted by the dissertation committee and the doctoral program.

COMMITTEE APPROVALS :

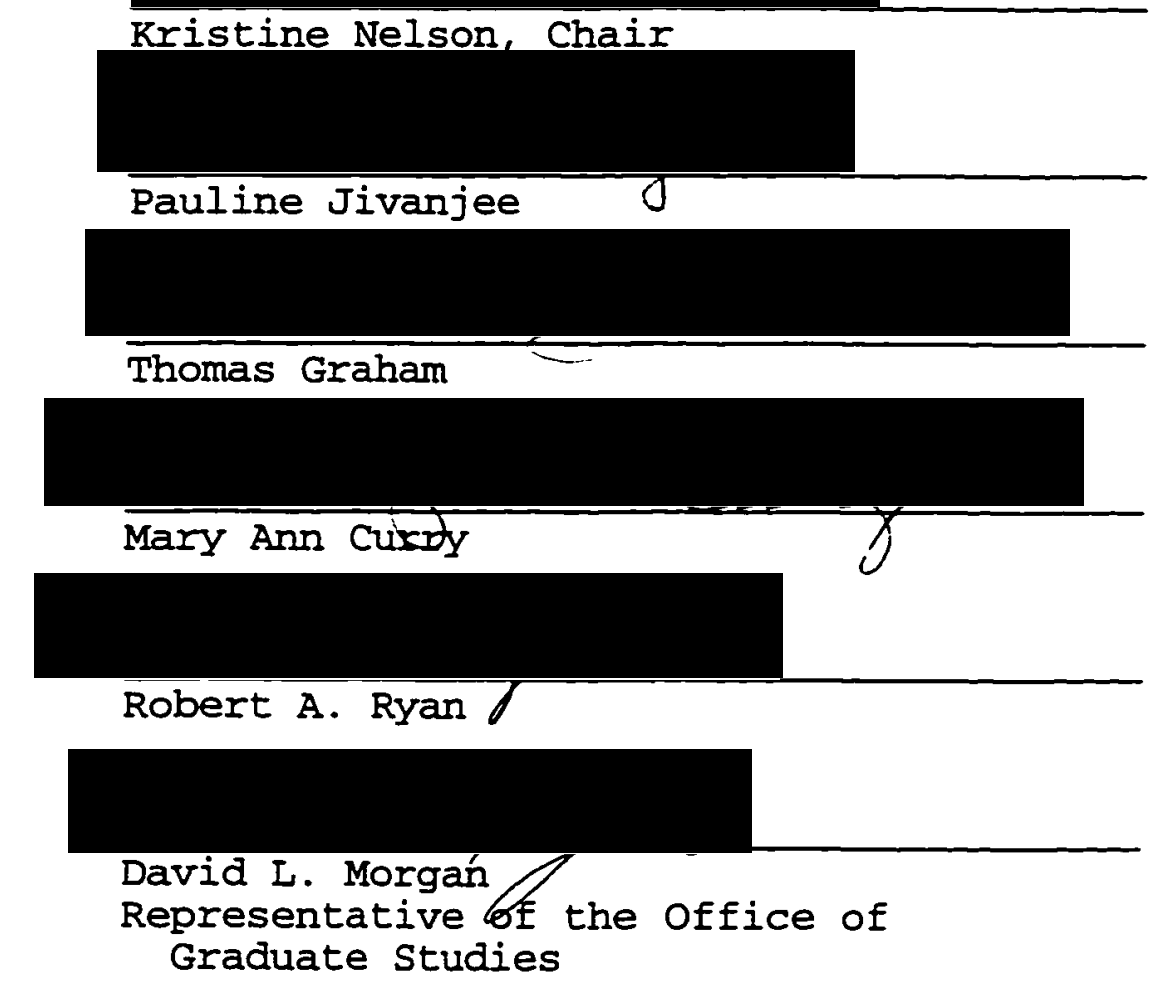

DOCTORAL PROGRAM APPROVAL :

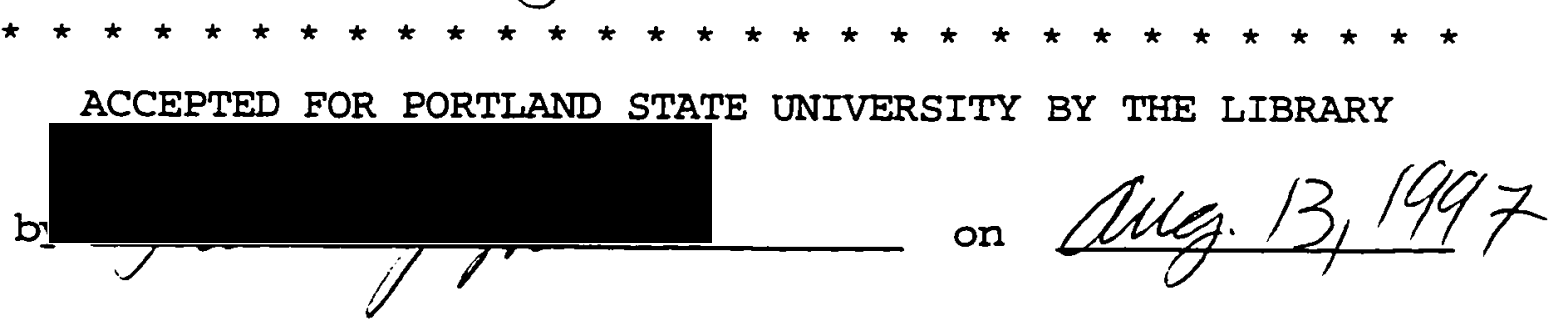

Joan/Shireman, Director, Social Work and Social Research Ph.D. Program 


\begin{abstract}
An abstract of the dissertation of Claudia Robin Long for the Doctor of Philosophy in Social Work and Social Research presented July 14, 1997.

Title: Grandmothers Laughing: Intergenerational Transmission of Cultural Beliefs Among Native American Women about Pregnancy and Childbirth
\end{abstract}

This dissertation reports findings from a qualitative study of intergenerational transmission of pregnancy and childbirth information among Native American women. Proposed is a theory of intergenerational transmission that explains four pathways used by Indian women to gain information about pregnancy and childbirth. Antecedent, consequent, and core elements are associated with the transmission process.

Discriminant sampling was used to identify the middle generation of Indian mothers and grandmothers, between 36 and 65 years of age, residing on or near the reservation, with experience of assimilation policies that had moved off-reservation temporarily. The researcher used the grounded theory method to analyze responses to the profile instrument, the Ethnic, Culture, Religion/Spirituality (ECR) instrument (Cross, 1995), May's (1982) social integration schema, and open-ended focus group interviews. Two focus groups were conducted, Group I with 4 women, and Group II with 3 women. 
The ECR questionnaire was used to describe aspects of cultural strengths believed to be associated with the presence of resiliency. May's (1982) social integration schema was used to describe attributes of social adaptation/integration to culture and as a way to predict susceptibility to problem behavior, such as alcohol use.

Interview data were analyzed using the method of constant comparative analysis. The resulting model of intergenerational pathways among Native American women described antecedent, consequent, and core elements of the transmission of culture.

In the process of cultural transmission, the middle generation of women identified with balancing both world views. Yet, in comparison with the Rural Oregon Minority Prenatal Project study (1995a), elders identified more with the traditional world, and the young Indian women did not identify with either world and were described as caught between two worlds. It is hypothesized then that urban Indian women, living off-reservation or with limited access to Indian culture, would identify more with the modern contemporary world rather than with the traditional Indian world. 


\title{
IN GRATITUDE AND ACKNOWLEDGMENT
}

\begin{abstract}
American Indian women have been a part of the storytelling tradition-both oral and written-from its inception, passing on stories to their children and their children's children and using the word to advance those concepts is crucial to cultural survival (in The Third Woman by D. Fisher, 1994).
\end{abstract}

This dissertation study is dedicated to all grandmothers who have been an inspiration to their families and who have passed on stories from their worlds.

Two women have been an inspiration in my two worlds--my Nez Perce Katsah Violet and my Irish Nana Griffith. I strive to continue to pass on their traditions in my own family. Therefore, my daughters, Lori and Lisa, and granddaughter Clorisa, it is crucial for you to pass on the stories that are told to you.

In telling this story about intergenerational transmission of culture, I am honored to have been surrounded by the expertise represented on my dissertation committee including: Kristine Nelson, Chair, child welfare researcher. She has a philosophy of life that epitomizes the resiliency approach; one that focuses on strengths rather than deficits; and she has an especially good sense of humor. Mary Ann Curry, OHSU, my practicum supervisor, is dedicated to women's health research; she exudes warmth and brilliance that is awe-inspiring. Pauline Jivanjee is a naturalistic researcher with a natural flair to empower and encourage self"discovery". Bob Ryan, Nanitch Sahallie Program, exemplifies Native American culture, acculturation, and spirituality. Tom Graham, my newest committee 
member and past co-worker has given me strength and encouragement from his incredible enthusiasm. And, David Morgan, Urban Planning and Graduate Office Representative, will remain in my memory, the charming and articulate guru of focus group methods that exemplifies excellence in qualitative study. The dissertation committee provided me with inspiration and motivation to succeed in my journey of discovery. Thank you.

Journey of Discovery on the Road Less Traveled

I was truly fortunate to have had this opportunity to take the road less traveled in my dissertation study by using a powerful and enchanting qualitative research design (similar to the story of Dorothy and the yellow brick road) which included scarecrow, lion, tin man, and so on. My journey, too, was enhanced by the wisdom gained.

Study participants shared their experiences and, therefore, increased our consistently punctuated among these women with joking, kidding, and satire, which created a relaxed atmosphere for sharing and connectedness, as well as a way to relieve stress. This dissertation study is written in their honor for making the journey of discovery possible.

Katsee yow yow (thank you) to Connie Evans, Bonnie Ewing, and Julie Simpson for reviewing the dissertation study and providing so much enthusiasm, encouragement and motivation to continue a journey of discovery fraught with 
setbacks. A special thanks goes to Darlene Maddox whose computer skills made completion of the final document possible.

And, to my Colleagues, Portland State University Students and Faculty (especially the second year G.S.S.W. Ph.D. cohort), Friends, and All My Relations, I share the honor of this degree, Doctor of Philosophy, with you. For, by your support in this journey of discovery, enhanced "cultural survival" will be by the discovery and awareness of resiliency aspects in the Native American community. These characters in the story, parallel the "little" people of $\mathrm{Oz}$ and helped to make the journey a success.

The journey was successful. Incredibly, I gained more than a dissertation research study. Similar to the ending of the story, I too discovered that I have a brain, a heart, and courage, and most importantly, I realized that I have always been "home." 


\section{TABLE OF CONTENTS}

LIST OF TABLES $\ldots \ldots \ldots \ldots \ldots \ldots \ldots \ldots \ldots \ldots \ldots \ldots \ldots \ldots$

LIST OF FIGURES $\ldots \ldots \ldots \ldots \ldots \ldots \ldots \ldots \ldots \ldots \ldots \ldots \ldots$ viii

CHAPTER

ONE PROBLEM OF POOR PREGNANCY OUTCOMES $\ldots \ldots \ldots 1$

Definitions

Nature of Problem

Statement of Problem

Significance of Study

TWO REVIEW OF THE LITERATURE $\ldots \ldots \ldots \ldots \ldots \ldots \ldots$

Barriers to Health Care

Native Americans: Cultural Beliefs and Practices

Federal Assimilation Policies

Acculturation Models

Coping Strategies

Resiliency Models

Constructing Reality

Summary

THREE REVIEW OF ROMPP AND DESIGN

Review: Findings of ROMPP Study and Pilot Work

Research Design

Sampling Procedures

Data Collection

Data Analysis Framework

Establishing Trustworthiness 
FOUR FINDINGS LEADING TO THE FINAL HYPOTHESES . . . . 63

Context of Sample

Study Participants

Findings

Categories Leading to Theoretical Framework

Overarching Theme: Balancing Two Worlds

Contradictory World View

Discovery

The Pathway

Grounding Hypothesis

FIVE THE MODEL, DISCUSSION AND IMPLICATIONS . . . . 129

Theoretical Model

Strengths and Limitations

Implications

Summary

APPENDICES

A RESEARCH APPROVALS $\ldots \ldots \ldots \ldots \ldots \ldots \ldots \ldots$

B CONSENT FORM $\ldots \ldots \ldots \ldots \ldots \ldots \ldots \ldots \ldots \ldots \ldots$

C INSTRUMENTS $\ldots \ldots \ldots \ldots \ldots \ldots \ldots \ldots \ldots \ldots \ldots \ldots$

D AUDIT DOCUMENTATION . . . . . . . . . . . . . . . . 169 


\section{LIST OF TABLES}

Table

Page

$1 \quad$ Maternal Risk Factors $\ldots \ldots \ldots \ldots \ldots \ldots \ldots \ldots \ldots$

2 Research Phases $\ldots \ldots \ldots \ldots \ldots \ldots \ldots \ldots \ldots \ldots \ldots \ldots \ldots$

3 Ways Indian Women Learn and Share $\ldots \ldots \ldots \ldots \ldots \ldots \ldots \ldots$

4 Chart Synthesizing Constant Comparison ............... 54

5 Bibliographic Sketch of Women Participants $\ldots \ldots \ldots \ldots \ldots$

6 Focus Group Questions $\ldots \ldots \ldots \ldots \ldots \ldots \ldots \ldots \ldots$

7 Pathway of Cultural Transmission by Elders and Young Indian Women About Pregnancy and Childbirth ............... 120 


\section{LIST OF FIGURES}

$\begin{array}{ll}\text { Figure } & \text { Page }\end{array}$

1 Categories and Relationships in Theoretical Model . . . . . . . . . . . 99

2 Model ............................. 128 


\section{CHAPTER ONE}

\section{PROBLEM OF POOR PREGNANCY OUTCOMES}

Statistically, all low income minority women in the United States are at risk for poor pregnancy outcomes due to racial status, poverty, or both (Lia-Hoagberg et al., 1990; Institute of Medicine, 1988). This includes Native American women who face additional barriers to receiving prenatal health care services. These barriers include conflicts between native cultural beliefs and practices and prevailing health care value systems. While there is strong evidence that minorities are substantially disadvantaged on most indicators of health and wellness, health services have not been adequately responsive to this groups' needs.

As products of both Euro-American culture and their own indigenous heritage, Native Americans face devastating social, economic, and environmental pressures of dislocation, racism, poverty, alcoholism, substandard reservation housing conditions, and hostile education systems (Dufrene \& Coleman, 1994). In addition studies have suggested that few social workers or health care providers have an understanding of the enormous problems attached to the social stresses of being dislocated away from traditional land bases because of U.S. government policies (Atkinson, Morten \& Sue, 1993; D'Andrea, 1994; Dufrene \& Coleman, 1994; Herring, 1990; Locust, 1988). 
Native Americans have been subjected to a long list of broken promises, discriminatory policies, and cruel and oppressive treatment by Euro-Americans (D'Andrea, 1994). It is not surprising, then, that studies depict Native Americans facing enormous problems including a rate of unemployment 3 to 11 times greater than that of the general population; a median income half that of the majority population; high school drop out rates exceeding $60 \%$ in many areas; arrest rates three times those for African Americans; and a rate of alcoholism double that of the general population (Henrich, Corbine, \& Thomas, 1990). The prevalence of alcoholism, fetal alcohol syndrome, and fetal alcohol effect is becoming a significant threat to the survival and functioning of future generations of American Indians (Steissguth, LaDue, \& Randels, 1988).

For pregnant women at risk, early and adequate prenatal health care has long been recognized as one of the most effective means of reducing unfavorable pregnancy outcomes. First, it provides the opportunity to screen and then treat problems. Second, it promotes positive health behaviors. And third, it has the potential to reduce stress, improve social support, enhance self-esteem, and reduce isolation (Curry, in press). Prenatal care that includes early screening and education about nutrition and health risks may improve maternal and infant outcomes. Yet between 1990 and 1992, 40\% of Native American mothers received 
no prenatal care in the first trimester of pregnancy (U.S. Department of Health and Human Services, 1996).

\section{Definitions}

The 1991 census reports show that over two million people identified themselves as American Indian/Alaskan Native in 1990 representing only $1 \%$ of the total population of the U.S. (U.S. Bureau of the Census, 1991). Although referred to collectively as American Indian, the 542 federally recognized Indian entities (tribes, bands, villages, communities, pueblos, Eskimos, and Aleuts) speak over 150 Indian languages. They also differ widely in their cultural and genetic heritage, economic resources, and lifestyles. The terms Indian and Native American are used interchangeably in this study to identify American Indians/Alaskan Natives. Legends/stories, and customs of a people will be defined as cultural traditions.

The quality of life in which there is an absence of disease and a presence of general well-being will define health. Inadequate prenatal care is defined as no care until the third trimester, fewer than five prenatal visits, or no care at all (Oregon Health Division, 1996). Early care is defined as care beginning during the first three months of pregnancy, regardless of number of prenatal visits (OHD). Indian Health Service Areas are the geographic areas "on or near" reservations in which Indian Health Services (IHS) has responsibilities (U.S. DHHS, 1996). The 
Portland IHS Service Area encompasses three states: Oregon, Washington, and Idaho.

\section{Nature of Problem}

High rates of inadequate prenatal health care among Native American women, substance use during pregnancy, and the consequence of high rates of infant mortality, primarily from Sudden Infant Death Syndrome and congenital anomalies, are the main elements of concern.

The Indian Health Services Report about health services for American Indians in 1991-1993 for the IHS service area populations indicates the following (U.S. DHHS, 1995):

The birth rate for American Indian Alaska Natives residing in the IHS service area was 26.6 (rate per 1,000 population) in 1991-93. It is 67 percent greater than the 1992 birth rate of 15.9 for the U.S. All Races population (p. 5).

The infant mortality rate for American Indians and Alaska Natives residing in the IHS services area was 8.8 (rate per 1,000 per live births) in 19911993 compared to 6.0 for the U.S. White population in 1992 . However, there appears to be under-reporting of Indian race on death certificates in at 
least three IHS areas - California, Oklahoma, and Portland. Therefore, mortality-based indices should be considered conservative estimates of the true values (p. 9).

In 1991-1993, 24.3 percent of all infant deaths in the IHS service area were caused by sudden infant death syndrome [SIDS]. This was followed by congenital anomalies at 23.0 percent (p. 45). On the contrary, the postneonatal mortality rate ( 28 days to 365 days after birth) for Indians was 1.6 and 1.9 times the U.S. All Races and White populations' rates in 1992, respectively (p. 41).

The Oregon Health Division (OHD) (1996) reports that among women giving birth in 1994, the percentage of Native American mothers receiving no prenatal care or inadequate care in Oregon was more than twice that of their white counterparts. Early care has been adopted as an Oregon benchmark (Oregon Benchmarks 2000, 1990) for the year 2000 to ensure that $100 \%$ of pregnant women begin prenatal care in the first three months. They were twice as likely to have an education level of less than twelve years (39.9\%) and were more likely to be unmarried (59.6\%) (OHD, 1996). 
American Indian mothers were at highest risk among all races in four out of eight maternal risk factors. Risk factors for Indian women compared to those for people of white race/ethnicity are shown on Table 1. More Native American infants $(9.8 \%)$ died within the first year, compared to $6.8 \%$ for Caucasian infants (OHD, 1996).

Babies in substance abusing families face greater risks of inadequate nutrition, abuse and neglect. In extreme cases, fetal alcohol syndrome is associated with significant use of alcohol (Qregon Benchmarks, 2000, 1990).

The Tribal Children's Protective Agency (TCPA) (1989) on the reservation studied in this dissertation reports that Native American women are likely to access prenatal care late in pregnancy or to receive no prenatal care. Further, they indicated that in $1989,30 \%$ of all births to this population occurred to high risk mothers who were active substance abusers or had used drugs during pregnancy.

Although these are all critical variables for further consideration and study, the focus of this dissertation will be on inadequate use of prenatal care by Native American women (Qregon Benchmarks, 2000, 1990; OHD, 1996, U.S. DHHS, 1996; TCPA, 1989).

In summary, the under use of prenatal care and the overuse of alcohol and drugs places Native American women at risk for poor pregnancy outcomes. 
Table 1

Maternal Risk Factors, Oregon Residents (OHD, 1996)

\begin{tabular}{lcc}
\multicolumn{1}{c}{ Risk factor } & \% White & $\begin{array}{c}\text { \% Native } \\
\text { American }\end{array}$ \\
\hline Inadequate prenatal care & 5.4 & 14.2 \\
Age $<18$ & 4.7 & 11.3 \\
$4+$ live births & 10.0 & 18.5 \\
Alcohol use & 2.6 & 6.3 \\
$<12$ years education & 20.8 & 39.9 \\
Unmarried & 27.5 & 59.6 \\
Tobacco use & 18.3 & 28.0 \\
\hline
\end{tabular}

Therefore, it is important to understand how to improve utilization of prenatal care among Native American women.

\section{Statement of Problem}

The high rates of infant mortality and use of drugs and alcohol among pregnant Native American women in Oregon are of momentous concern. Native American prenatal health care has been identified as a priority in the Oregon Health Benchmarks for the year 2000. Objectives are based on inadequate prenatal care rates, rurality, poverty status, and unmet health needs (Oregon Benchmarks, $\underline{2000}, 1990)$. To improve birth outcomes for Native American women, there is a need to increase early and consistent prenatal health care use. 


\section{Significance of Study}

\section{Assumptions}

The study described here contextualizes the prenatal health beliefs and behaviors of women within a socioeconomic, cultural, and political framework, thus revealing structural constraints on the health choices available to individuals. Individual responsibility for health and making the correct health behavior choices are assumed. Because the concept of interdependence among socioeconomic, cultural, and political spheres is not always contained within Western health models, prenatal health services may operate in isolation from other social and welfare services. This leads to the assumption that the existing Western health model used as a framework in service delivery to rural Native American women may not be culturally appropriate. Improvements in the design and delivery of prenatal health services should be sensitive to and accommodate this cultural variation.

\section{Rationale for Dissertation}

This study builds on a previous qualitative study contained within the Rural Oregon Minority Prenatal Project (ROMPP) study (1995a, 1995b, 1990) which will be discussed in Chapter Three. This dissertation was designed to identify health care barriers by describing individual perspectives of the transmission of cultural health beliefs about pregnancy and childbirth. The aim was to build a 
substantive theory about the intergenerational transmission of cultural health beliefs in the context of pregnancy and childbirth experiences through interpretation of the subjective experience of Native American women. 


\section{CHAPTER TWO}

\section{REVIEW OF THE LITERATURE}

The purpose of the literature review is to survey the field, to develop an understanding of what is known, and to identify gaps in knowledge that may give direction to the research. The process of qualitative research is one of discovery, and some suggest (Sherman \& Reid, 1994) that reviewing previous work compromises openness to discovery. However, theoretical sampling of the literature was used to expand on and refine the concepts and theory that had already been developed in the previous ROMPP study (Sherman \& Reid, 1994). Initially, emergent themes from analysis of the data directed ongoing theoretical literature sampling of resiliency and risk factors among Native American extended family systems, and of assimilation and acculturation processes.

Strauss and Corbin (1990) suggest that use of the literature can be viewed as an ongoing process. The aim is to discover relevant categories and the relationships among them and to put categories together in new, rather than standard ways (Strauss \& Corbin). Phenomena are explained in light of the theoretical framework that evolves during the research itself, eliminating the constraint of theory that may or may not apply. Since discovery is the purpose, it was only after a category had emerged as pertinent that technical literature was revisited. 
The focus of the first section of the literature review is barriers to health care, followed by a section on cultural beliefs and practices of Native Americans. A consideration of federal assimilation policies and their consequences is followed by a discussion of acculturation models and coping strategies used in families. The resiliency models and ways of constructing reality among Native people are described.

\section{Barriers to Health Care}

Cultural barriers to health care are complex and interrelated. Barriers identified in the literature that influence access to and retention of prenatal health care for minorities include: (a) systems barriers at the macro level, (b) provider barriers at the micro level, and (c) personal barriers at the client level.

\section{System Barriers}

These include health systems and their lack of appreciation for cultural approaches to illness and healing (Luckey, 1994; Parker, et al., 1992; Mokuau \& Fong, 1994). Meadows (1991) stresses the importance of health care systems learning to communicate effectively with a clientele characterized by everincreasing cultural diversity. Health systems need to have an understanding of health-related beliefs and customs of their culturally-diverse clients, and of how culture influences health, health care seeking, and compliance with treatment programs. The importance of understanding multi-cultural values relative to health 
and illness practices and factors that influence health-care systems have been identified in studies of diverse cultural groups (Agbayani-Siewert, 1994;

D'Avanzo, 1992; Mokuau, 1990; Russell \& Jewell, 1992; Uba, 1992; Villarruel \& de Montellano, 1992; Woodward \& Edouard, 1992).

Mondragon (1993) suggests that health disparities between white, racial, and ethnic minorities in the U.S. are partly the result of assumptions that place the responsibility for maintaining health on individuals. Yet, contemporary health care models offer limited options or resources to elicit change.

\section{Provider Barriers}

Unfriendly and disrespectful health care providers can be powerful barriers to care. Provider barriers include interpersonal characteristics such as disrespect, hostility, and paternalism (ANA, 1987; Schupholme, et al., 1991). Lack of cultural awareness and sensitivity to minority groups among individual providers can also pose barriers to receiving health care (Parker, et al., 1992; Luckey, 1994). Although impossible, Khazoyan and Anderson (1994) suggest that there be an attempt by health care providers to understand all cultures and their distinct qualities, values, networks, and expectations, and that when this goal is attained, all individuals from all cultures will be in a position to receive the best possible health care. 


\section{Personal Barriers}

Devaluing cultural beliefs that are inconsistent with the Western health model creates personal barriers between the client and utilization of health care. Barriers to access and retention in prenatal health care among pregnant minority women involve personal beliefs, cultural practices, and attitudes (Amed, 1990). These include: fear of medical personnel, low concern regarding health risks, a belief in the "naturalness" of pregnancy, and prior negative experiences with the health system. Individuals of diverse ethnic backgrounds often have beliefs about health, disease, and treatment that vary significantly from the existing Western health model (Congress \& Lyons, 1992).

In summary, in addition to the multiple barriers that confront low income women including economic, transportation, and child care-related issues, rural, low income Native American women face additional challenges. These include lack of available and appropriate providers and negative provider attitudes (Institute of Medicine, 1988; Richardson, 1988). Conflicts between cultural beliefs and practices and prevailing community values will be the focus of this dissertation.

Native Americans: Cultural Beliefs and Practices

\section{Value Orientation}

Vast cultural differences between Native American and Euro-American culture include valuing harmony with nature rather than mastery over nature, a 
present rather than future orientation, a preference for natural rather than for scientific explanations of phenomena, cooperation rather than competition, group relations and extended family relations rather than individuality, humility rather than attention-seeking, a deep respect for elders rather than a reverence for youth, and sharing of wealth rather than saving for the future (Dubray, 1985; Sanders, 1987; Thomason, 1991).

\section{Relational World View: Balance}

In the Native point of view, systems come into harmony as Native Americans retum to their culture and the spiritual way. Balance, the desired state wherein one is in harmony with nature, is a central concept in understanding the symbolism of the Circle (Garrett \& Garrett, 1994; Garrett \& Myers, 1996).

The medicine wheel, a sacred Native American symbol, reminds us that progression or growth is indeed circular or cyclical in nature and illustrates the relational world view:

Medicine wheels are circles that have horizontal and vertical lines through the center and symbolize the earth, lines represent pathways, and the four colors (black, white, red, and yellow) symbolize the four races of humanity and the four directions (Dufrene \& Coleman, 1994, p. 147). 
In the circle of the medicine wheel the mental, physical, spiritual, and contextual parts of a human being are represented (Cross, 1995; Garrett \& Garrett, 1994; Garrett \& Meyers, 1996). The intricate system of interdependence among these parts exists in a dynamic state of harmony and balance. Energy emanates from each form of life in relation to every other living being; hence, all life is worthy of respect and reverence (Garrett \& Garrett, 1994; Garrett \& Meyers, 1996). The center of the medicine wheel, where the four spokes meet, represents the place that can affect any of the four parts. It is there, in the center, at the core, that real change happens.

Traditional Native American culture views health as seeking a balance of emotional, mental, physical, and spiritual aspects of life. It is no wonder then that the relational world view of native people is based on a holistic frame of reference. Currently there is a revitalization of these traditional cultural beliefs and practices among Native Americans (Dufrene \& Coleman, 1994).

\section{The Extended Family}

The Native American extended family and kinship network functions on the principle of interdependence, group orientation, and reliance on others. Extended family systems may be the most striking feature of Native American culture. Studies have indicated that Native Americans are more firmly rooted in the family 
as a source of identification than Euro-Americans, regardless of socioeconomic status or geographic locale (Lum, 1993). The family is distinguishable by a definition of membership that extends into several generations and can be informal. Attneave (1969) suggests that the extended family has the potential for aiding positive therapeutic outcomes within the Native American context.

The extended family and tribe take precedence over all else. Among tribal members, a strong sense of belonging relies on cultural ties and social relationships, as well as a sacred sense of connection with one's ancestry and tribal history (Garrett \& Garrett, 1994). As a result, many Indians will describe some aspect of their family or tribal heritage and affiliation when asked to describe themselves. In contrast, worth and status in Euro-American society are based on what you do or what you have achieved (Garrett \& Garrett, 1994).

\section{Cultural Pathway}

A few studies, although not specific to women, suggest that Native Americans with more traditional beliefs about health respond better to treatment when traditional healers, extended family, grandmothers and elders of the Native American community are involved (LaFromboise, 1988; LaFromboise, Trimble, \& Mohatt, 1991; Locust, 1985; Thomason, 1991). Native American elders have been identified as playing a central role in the daily activities of Native American family life (Red Horse, 1980). Grandmothers are recognized as part of the existing natural 
helping system within Native American communities and as primary cultural transmitters about pregnancy and childbirth among Indian women (Bushnell, 1991; Horn, 1992).

\section{Federal Assimilation Policies}

Federal assimilation policy has threatened the identity, social support systems, and traditional roles among Native American women (Bushnell, 1991; Horn, 1992). Removal policy in 1953 called for the termination of federal responsibility for American Indians as quickly as possible. In 1954, relocation policy encouraged Indian migration from the reservation into urban centers. Native language and customs were forbidden in federal Indian boarding schools in order to weaken oral tradition and connections with tribal culture (Fleming, 1992; Cross, 1986). Being robbed of their stories by the propagandizing and punishing of children in schools, Native Americans lost some of their "cultural sinew," their collective memories, and their hopes (DeLoria, 1969). Indian culture, tribal organization, and Indian family structure were expected to collapse and to be absorbed into the larger society.

\section{Loss of Identity and Roles}

The effects of federal assimilation policy in disrupting traditional Indian beliefs and practices have been profound (Beane, Hammerschlag, \& Lewis, 1980; DeLoria, 1969; Williams \& Ellison, 1996). Forced acculturation, racism, and 
discrimination have been acknowledged as blatant threats to personal integrity that are continually experienced by Native American people. Policies have also interrupted the traditional roles of indigenous women who have long been recognized as primary transmitters of wisdom through native oral tradition (Medicine, 1987; Long, 1995).

Although discussions of specific barriers to prenatal care encountered by Native American women are missing from the studies, views about childbirth and general health beliefs and traditional roles have been examined. A study of Northwest coastal Native American women about childbirth perceptions was conducted by an outside researcher (Bushnell, 1991). However, women between the ages of 28 and 61 were unwilling to participate or to share information. Participants acknowledged that the traditional learning pathway about pregnancy and childbirth was through elder women, but the pathway was often unavailable to younger women. Younger women were described as becoming more dependent on contemporary community resources.

Horn (19982) found similar themes in a study of another Northwest coastal Indian tribe. Prenatal care was perceived as "pampering the mother" since pregnancy was viewed as a normal event not requiring medical intervention. Even so, maintaining a regimen of exercise, healthy diet, and abstinence from alcohol and drugs were encouraged for pregnant tribal women. Female relatives 
traditionally functioned in the role of midwife and were considered a major source of information. Acculturation processes resulted in abandonment of many traditional ways including the use of tribal medicines and birth practices.

A study about health perceptions noted that the majority of older urban American Indians had given up or forgotten traditional health practices (Hatton, 1994). Major reasons identified were: untimely deaths of traditional healers and transmitters of traditional practices; forced assimilation policy requiring attendance at federal Indian boarding schools that actively discouraged traditional practices; increasing accessibility of biomedical and Western treatments and concomitantly decreasing availability of traditional healers; and a lifetime of interactions with urbanized multi-cultural community health care providers. Traditional practices were considered by Native American adults only after Western biomedical treatments had failed.

In addition, the inactivity associated with old age in Euro-American society has coincided with a general devaluing of elders in the society (Garrett \& Garrett, 1994). Indian children learn to perceive elders, the keepers of sacred ways, as being useless and the effects have, in many cases, split the Native American multigenerational support system by removing elders from their roles as honored persons in the community (Garrett \& Garrett, 1994). 


\section{Acculturation Models}

Models of acculturation can be misleading as small scale replicas of reality. However, looking at acculturation from the health approach (Choney, BerryhillPaapke, \& Robbins, 1995) rather than deficit approach helps in understanding Indian acculturation. Specifically, May's (1982) model that looks at the association between alcohol use and other risk-generating behaviors and level of acculturation will be explored.

Federal assimilation policies have contributed to the acculturative process among Native Americans. Historically, American Indians have felt the loss of their freedom to express themselves in traditional ways as a form of oppression (Locust, 1988; Williams \& Ellison, 1996). Ethnocentrism is based on the premise that Euro-American ways are superior to Indian ways. Acculturation is a major factor shaping the Native American world view (Choney et al., 1995).

There are varying levels of acculturation exhibited by Indian people representing diverse tribal groups with different customs, traditions, and beliefs, and, from a variety of settings including rural, urban, or reservation (Garrett \& Garrett, 1994). However, there remains a high degree of psychological homogeneity, a certain degree of shared cultural standards and meanings based on common core values that exist for traditional Native Americans across tribal groups (Dubray, 1985; Heinrich et al., 1990; Peregoy, 1993; Sue \& Sue, 1990). 
Culture and acculturation, in addition to other variables, must be considered in the study of birth outcomes and Native American women. Rather than looking at a dichotomous view of acculturation, a variety of cultural positions and fluidity are taken into account as the individual moves between traditional Indian and EuroAmerican culture.

May's (1982) social integration continuum suggests types of cultural adaptation which contemporary Indian individuals make that reflect on susceptibility to negative coping behaviors, such as substance abuse. These cultural types are identified by May (1982) as traditional, modern, both, or neither.

In summary, acculturation is a multi-dimensional process that may have both positive and adverse effects on particular health outcomes (Zambrana \& Ellis, 1995). Attention to the health-enhancing and the stress-producing aspects of acculturation for women of color and ways in which they interact with socioeconomic status and other risk factors and their pervasive effects on health and well-being has recently been identified in the literature (Adams, 1995).

\section{Coping Strategies}

Coping strategies for handling acculturative stress and intergenerational trauma include health-enhancing aspects such as resiliency and other protective factors and stress-producing aspects such as alcohol abuse and family violence. 


\section{Resiliency: Cultural Maintenance}

Choney et al., (1995) suggest removal and relocation were not successful methods of assimilating Indians into Euro-American cultural standards. Federal assimilation policy aimed at destroying cultural systems resulted instead in strong, resilient family systems that provided protective factors within Native American tribal groups, especially among women.

In contrast with the "deficit model" approach that assumed superiority of Euro-American culture over American Indian culture, the "health model" approach (Choney et al., 1995) looks at retraditionalization evident today and, consequently, the strengths at all levels of acculturation. In this approach, Native language, spirituality, and social/environmental influences are also taken into consideration.

Lum (1993) focuses on the maintenance of culture in the lives and practices of people of color as a means of overcoming social problems. Culture is viewed as a source of strength and renewal, a protective factor. Cultural practices based on ethnic heritage can be documented in minority people of color's community churches, social organizations, politics, language, schools and related institutions (Lum).

\section{Indian Humor}

Humor, although multifaceted and an elusive concept, is a cultural practice used among Native Americans as a major source of strength and connectedness. 
As a coping strategy, it conveys messages that might be censored if expressed or acknowledged directly (Herring, 1994). The concept includes wit, laughter, joking, comedy, kidding, teasing, clowning, mimicking, satire, and enjoyment of the imperfect (Robinson, 1978). Laughter is recognized in Indian circles as a way to relieve stress and to create an atmosphere for sharing and connectedness as part of a group (Garrett \& Garrett, 1994). Teasing is a prominent feature of Native American humor and as a major component of Indian socialization processes that keeps everyone humble and part of a group (Garrett \& Garrett, 1994). Indian humor, therefore, must be included when considering resiliency and coping strategies used among Indian women.

\section{Substance Abuse and Family Violence}

A preponderance of evidence suggests culture and acculturation influence drinking patterns and habits of Native Americans (Choney et al., 1995). In a study by Tom-Orme (1993) Native American women considered alcoholism to be the leading health problem among the general Indian population. Alcohol use during pregnancy is of particular concern due to its association with fetal alcohol syndrome (FAS). Although there are few studies in this area, one study among the Northern Plains Indians indicated an FAS rate of 8.5 cases per 1,000 live births (Duimstra, Johnson, Kutsch, Wang, \& Zentner, 1993). 
In 1985, due to the concern for increased infant mortality rates, the lack of or inadequate utilization of prenatal care, and high alcohol use by pregnant mothers a strategic plan to target prenatal clients and Indian communities was developed by the IHS (Rhoades, Mason, Eddy, Smith, \& Burn, 1988). These studies suggest a relationship among drinking patterns, cultural values, and acculturation.

The incidence of domestic violence among Native Americans has been attributed to social service systems that do not recognize the problem, the deterioration of the traditional family structure, alcoholism, and the lingering effects of historical oppression (Wilson, Thomann, \& Gish, 1993). Spousal, child, and elder abuse have also been associated with alcohol and drug abuse (TomOrme, 1995). The problem is seen as multifaceted and complex requiring the cooperation of varied helping professions within Native American populations.

\section{Resiliency Models}

By learning to assess resiliency and strengths related to invulnerability and protective factors, we can begin to learn about human diversity from a non-deficit perspective (Begun, 1993). This provides a framework to look at resiliency in Native American cultural systems and relates resiliency to culture and acculturation processes.

Cross (1995) suggests that the relational world view of health, with its roots in tribal cultures, is a way to understanding resilient behavior. In this world view, 
a problem is perceived as circumstantial, residing in the relationship between and among various factors. The four major factors within the Native American relational framework represent the context, the mind, the body, and the spirit. When considered together, the model is viewed as an interdependence of relationships that explain resilient family behavior. Cross suggests that "it is the constant change and interplay among various forces that account for resilience" (p. 154).

\section{Constructing Reality}

The strength of the relational model is that it gives us a way to understand how Native American people restore balance in their lives and deal with oppression through traditional beliefs, customs, stories, and legends. Tribal people depend on oral history by way of stories, songs, and legends as major cultural pathways that are not usually written down. Much of the strength and meaning of Native American oral history is derived from the relationship between the oral historian and the listener, and from a mutually understood social and cultural context in which language plays a crucial role.

It is argued that by assisting in the construction of meanings, social workers can help strengthen and embolden the traditions of the group to help clients move into the larger and often oppressive world (Saleebey, 1994). Traditions and stories shared among Native American women are included in this study. 


\section{Summary}

The constant comparative method continually directed and re-directed the literature reviewed as themes continued to emerge. Barriers to health care were identified at three levels: system, provider, and personal. In order to ensure theoretical sensitivity of the researcher, a review of the literature about Native American cultural beliefs and practices, the Native American value orientation, the relational world view, and the function of family and extended kinship systems were explored.

Boarding school and relocation polices and their consequences to Indian women were described in analysis as emergent themes and therefore, were reviewed in the literature. Consequences of federal assimilation policy were identified in the literature as the interruption to traditional female roles and therefore, to the cultural pathway. The literature indicates that some Indians residing in urban communities have given up or forgotten traditional health practices. Devaluing elders in the society has also been identified in the literature with the breakdown in the transmission of culture. The traditional health regimen in preparation for childbirth in Indian communities is said to parallel good western prenatal care. 
May's (1982) model of social integration was discussed. The set of four cultural positions take into account the fluidity between traditional Indian and Euro-American culture.

Cross' (1995) resiliency model was described. The approach focuses on cultural strengths rather than deficits and identifies protective factors within Native American tribal groups. Indian humor is one aspect of cultural resiliency used in Indian communities. Substance abuse and family violence in Indian families were also discussed. Cross' resiliency model was reviewed as an example of explaining resilient family behavior in Indian families. 


\section{CHAPTER THREE}

\section{REVIEW OF ROMPP AND PILOT FINDINGS, DISSERTATION DESIGN AND METHODS}

In this chapter the findings of the ROMPP study (1995a) and pilot work (1995b) that led to this dissertation study will be reviewed. Then the emergent design and methodology of the dissertation study will be described.

Review: Findings of ROMPP Study and Pilot Work

The purpose of the larger ROMPP study (1990) was to improve the birth outcomes of pregnant Native American and Hispanic women living in rural Oregon by providing nursing case management and the services of indigenous outreach workers to project participants. It was grounded on three basic premises: (a) that interventions used with minority and culturally diverse clients should acknowledge and incorporate the beliefs, values, and health practices of clients' native cultures; (b) that successful enrollment of high risk minority clients in health care, particularly those in rural areas, depends on removal of barriers to seeking care-cultural, language, geographic, social, transportation-related, financial, educational, and legal--as well as the barrier of mistrust; and (c) that use of indigenous community members native to the targeted minority group, in partnership with nurses, is the appropriate mechanism through which rural minority clients can be enlisted into health care services--in this case early and continuous prenatal care. 
One of the aims of the qualitative ROMPP study (1995a) was to describe barriers to care. Substantive information about the beliefs, values, and health practices of Native American women was missing from the original research design that relied on quantitative research data. The decision was made, therefore, to hold focus groups of elders and of women of childbearing age. It was expected that a qualitative study of the social reality of Native American women would complement the quantitative data. Traditional and non-traditional cultural values and belief systems were considered by enlisting participation of elder women identified by the community as keepers of cultural traditions and younger, pregnant mothers, some of whom were ROMPP participants. Therefore, information about both past and present lived experiences within native and contemporary health care systems was obtained.

The target population was $\underline{\underline{N}}=52)$ self-identified elder grandmothers and young mothers of child-bearing age, living on two Native American sites in rural Oregon. The on-reservation site was referred to as the reservation site. The other site, called the tribal site, had lost reservation status in the 1950s during the termination period and was located in a town with close proximity to tribal members.

Demographics were not collected from these women in the ROMPP Study (ROMPP, 1995a, 1995b). Eligibility criteria were that participants be Native 
American mothers residing on or near the reservation/tribal site. Elders and young women were self-identified.

\section{Pilot Work}

Pilot work for this dissertation was conducted to fill a gap perceived after the focus groups of elders and young mothers were conducted. The pilot work consisted of a deliberately chosen group of five women from seven prior focus groups from the ROMPP study. The pilot focus group were younger than the elder groups, but not of child-bearing age. Findings from the pilot work confirmed the need to conduct a study with the middle group of women. See Table 2 for research phases that describe the number of participants in each study phase.

\section{ROMPP Findings}

In the ROMPP study elder women and younger pregnant mothers revealed a breakdown in the transmission of traditional cultural beliefs about pregnancy and childbirth (Long, Curry, \& Burton, in review). Elders from the reservation site remembered learning traditional cultural wisdom about pregnancy and childbirth from elders. This access was recognized as the traditional cultural pathway. Elders from the tribal site were most directly impacted by assimilation policy. 
Table 2

Research Phases

\begin{tabular}{lccc}
\hline & Phase I & Phase II & Phase III \\
\hline Description & ROMPP study & Pilot work & Dissertation study \\
Sample size & $\underline{N}=52$ & $\underline{\mathrm{n}}=5$ & $\underline{\mathrm{N}}=7$ \\
When conducted & $1994-1995$ & 1995 & $1996-1997$ \\
\hline
\end{tabular}

Their tribal status had been terminated for a period of time, and the elders from this tribal site did not have a land base, nor did not have access to their traditions.

In the ROMPP study (1995a), young Indian women learned about pregnancy and childbirth mostly in a combination of ways: their mothers, from contemporary health care providers, and from reading. Often they did not have access to the traditional pathway with elders. Young Indian women from the tribal site also identified being separated for a number of years from accessibility to traditional cultural wisdom. This loss was primarily recognized as resulting from tribal termination and effects of assimilation policy. These women were also interested in being supportive to other young Indian women. See Table 3 for ways that these two generations learned and shared cultural health beliefs.

Women from both generations and sites perceived that the breakdown in transmission between elders and young women needed to be repaired. Elders 
Table 3

Ways Indian Women Learn and Share (ROMPP, 1995)

Elder Generation

Learned traditional beliefs from Elder women.

- Shared mostly traditional beliefs with younger family women.

- Perceived a loss of traditional roles in transmitting culture beliefs.

Would like to be more involved with health care providers and young women.

$\checkmark \quad$ Utilized a traditional (Indian) world view.

\section{Youngest Generation}

- Learned mostly contemporary beliefs from mothers, reading, and Western health care providers.

- Shared mostly contemporary beliefs with other young women.

- Perceived a loss of access to traditional pathway among Indian women.

- Would like to see prenatal care include Indian Elders' wisdom.

- Utilized a core traditional (Indian) world view, but adapting to a contemporary (linear) world view. 
recognized that grandmothers were not always available to family members, as they had been in the past, and also realized the need to support and teach young pregnant women about cultural health beliefs and practices. Younger women were interested in learning from elders, but were frequently without access to grandmothers' wisdom.

It was realized in our focus group interviews that elder participants were sometimes less than 65 years old, and in one instance, well over 80 years old. The young women were mostly less than 35 years old.

The ROMPP Study and pilot work (ROMPP, 1995a; 1995b) provided insight into the complex nature of intergenerational transmission of cultural beliefs about pregnancy and childbirth perceived by elders and young women. They also provided insight into women's perspectives when confronted with the need to make a decision about utilizing health care or not, and if so, from traditional or Western health service providers.

A breakdown in the intergenerational transmission of traditional health beliefs among young and elder Indian women emerged as the central theme. Findings suggested that the contemporary Western model be reconceptualized to provide for traditional cultural wisdom (Long, et al., in review). This model would 
incorporate Indian elders in collaboration with licensed health care providers to provide for the majority of care. The focus would be on culturally-relevant issues identified by Native American women.

Findings also identified one generation of women that had originally been omitted in the ROMPP Study as the "missing link" in the exploration of the intergenerational transmission of cultural beliefs among young women and elders. The purpose of this dissertation study is to explore that pathway by interviewing the middle group of women. This generation of women is important because Indian women between the ages of 28 and 61 have not been included in research about perceptions of childbirth (Bushnell, 1991). The pathway of cultural transmission of health beliefs and practices is unknown for this group of women. Therefore, this dissertation study was designed to develop knowledge by describing their specific situations.

Findings from the ROMPP Study (1995a) led this investigator to the distinct impression that understanding the psychological, social, cultural, and historical conditions under which health care is provided to Native American women would produce hypotheses regarding the interplay between the transmission of cultural health beliefs and non-utilization of contemporary health care. 
Acculturation and resiliency models were also identified to help build a theoretical foundation for a comprehensive understanding of the transmission of cultural beliefs and practices in a changing world, as perceived by Native American women.

\section{Research Design}

\section{Constructivism}

The selection of constructivist inquiry is consistent with the aim of the study to develop knowledge by describing individual situations. Constructivist inquiry and a qualitative research design using grounded theory methodology fit the cultural construction that all elements of a Native American woman's life form a complex interacting whole.

The purpose of the grounded theory method is to build theory that is faithful to and illuminates the area under study (Glaser, 1978; Sherman \& Reid, 1994). Constructivism's assumption is that social reality changes (Lincoln \& Guba, 1985; Guba \& Lincoln, 1994, 1989). Reality (ontology) in the constructivist paradigm is understood as mental constructions, socially and experientially based, local and specific in nature, and dependent for their form and content on the individual or group holding the constructions (Guba \& Lincoln, 1994). Findings (epistemology) are literally created in the interactive relationship of the inquirer and object of inquiry. 
Symbolic interaction is the conceptual framework for grounded theory (Morse, 1994). The basic premise of symbolic interactionism is that persons construct meanings for phenomena based on their interpretations of interactions they have had with one another within a social context (Morse, 1994). The meanings that participants place on their interactions with others in the framework of family and cultural life, health care beliefs and practices, and in other contexts, will play a crucial role in the transmission of cultural beliefs. The aim of this study was therefore, to build a substantive theory about the transmission of cultural health beliefs in the context of pregnancy and childbirth experiences through interpretation of the subjective experience of Native American women.

Because meaning is determined by the context, the research was emergent in design and dependent on the interaction between the investigator and context and not fully predictable or known until it was observed. Design flexibility is a crucial feature of qualitative inquiry (Marshall \& Rossman, 1995). Although consultation with members of the Dissertation Committee was sought regarding minor revisions in the emergent design (whether or not to conduct further focus groups, permission to include a questionnaire to measure resiliency, and an extension in the time line) there were no major changes in design.

In qualitative research the researcher is the instrument of measurement and the primary data gathering instrument (Lincoln \& Guba, 1985). Learning about 
multiple perspectives and analytic interpretations is required of the qualitative researcher. As the primary data collection instrument, the researcher needed skills and knowledge of the subject and of the methodology. Preparation included the researcher's personal and professional history of working and living within Native American family cultural systems, familiarity with Indian policy issues and resiliency models gained from work experience and doctoral studies, and two years of direct involvement and participation in the ROMPP qualitative research study.

Theoretical sensitivity is having insight, the ability to give meaning to data, the capacity to understand, and the capability to separate the pertinent from that which isn't (Glaser, 1978). The ongoing process of increasing the researcher's knowledge base increased theoretical sensitivity. By observation and through negotiation with the participants and peer reviewers, a set of themes about cultural transmission that were consistent and reliable emerged.

A qualitative approach assumes the importance of the participants' perceptions (Taylor \& Bogdan, 1984) as it explores the meanings of the phenomenon (Marshall \& Rossman, 1995). Tacit knowledge is preferred in a study about cultural transmission because it is impossible to explain everything in language form. Some things must be experienced to be understood, or implied.

Thick description used in qualitative research can be defined as stressing the interpretation of cultural meaning (Lincoln \& Guba, 1985) "necessary to enable 
someone interested in making a transfer to reach a conclusion about whether transfer can be contemplated as a possibility" (p. 316) A thin description simply reports facts, independent of intentions or circumstances; a thick description, in contrast, gives the context of an experience, states the intentions and meanings that organized the experience, and reveals the experience as a process. Geertz (1994) suggested that culture is a context; something which can be intelligibly, that is "thickly" described

\section{Ethical Issues}

To gain administrative approval to conduct the research study on the reservation with tribal women, contacts were made with (a) the Tribal Council, (b) the Health and Human Services Subcommittee, and then, upon obtaining tribal consent (c) the administrator of the Indian Health Services clinic to discuss the plan for recruitment, time line, and logistics involved.

This study was approved by the Portland State University Institutional Review Board in order to protect the rights of the participants and tribe. Adherence to the Tribal Research Review policy assured that all reasonable efforts had been taken to protect confidentiality and anonymity. (See Appendix A for documentation.)

Audio and video tapes, and other documents are scheduled to be destroyed upon completion of the study. All recorded interviews and personal information 
were stored by identification codes in a locked cabinet. Animal "creation" names from Indian legends were used to identify and code participants rather than first names. In appreciation of each participant's time and contribution, a minimal gratuity was paid at the conclusion of the interviews.

\section{Sampling Procedures}

Local context and the human story, as a reflection of reality, are primary goals of qualitative research, and not "generalizability" (Miller \& Crabtree, 1994). The integrity of the qualitative approach used in the dissertation was established by meeting criteria that establish trustworthiness and, therefore, generate confidence in the findings. Transferability, analogous to generalizabılity, criteria will be discussed in the Trustworthiness section at the end of this chapter.

Analysis constantly guided data collection, therefore, sampling and analysis occurred simultaneously. One additional focus group was chosen on the likelihood that it would advance the development of findings, referred to as theoretical sampling (Glaser \& Strauss, 1967; Strauss \& Corbin, 1990). This continued until no new information was found, referred to as theoretical saturation (Glaser, 1978; Glaser \& Strauss, 1967).

As concepts became repeatedly present or became absent, categories emerged. Therefore, by "sampling events rather than persons and their properties and dimensions, they became conceptually related" (Glaser \& Strauss, 1990, 
p. 177). In this dissertation study, at the point at which the researcher was unsure about still discovering new information (Strauss \& Corbin, 1990), the choice was made to conduct another focus group and also to expand and diversify the demographics from the first sample.

Since selective coding was used "to integrate the categories to form theory, validate the integrative statements of relationship, and fill in categories that needed further development," sampling became very "directed and deliberate," referred to as discriminate sampling (Strauss \& Corbin, 1990, p. 187). A consideration in this dissertation study was representativeness of the sample and how much it resembled the population in terms of specified characteristics (Strauss \& Corbin, 1990). The section on the sample will later discuss examples of discriminate sampling.

\section{Recruitment Process}

The recruitment process defined what kind of women were recruited into both focus groups. A list of twenty names and points of contacts were referred to the researcher by the in-house IHS public health nurse. Points of contacts (telephone numbers) were either the place of employment or of a relative. The researcher made an initial introduction by telephone and brochures about the study were faxed to the initial eleven interested respondents. Follow-up telephone screening calls were made to the eleven candidates. Screening interviews are seen 
as a useful approach for locating participants who fit categories and are interested in participating (Morgan, 1988, 1993).

Eligibility criteria included: (a) tribal affiliation, (b) age range between 36 and 65 years old, (c) experience with federal assimilation policies, (d) motherhood, and (e) willingness to complete questionnaires, to be audio/video-taped, and to participate in individual follow-up interviews (totaling at least 3 hours). Eligibility criteria were based on the pilot work (ROMPP, 1995a) and on discussions with research experts in prenatal health care and Native American culture. The more homogeneous the population of interest is in terms of background and role-based perspectives, the fewer groups were needed (Morgan, 1988). In this study, two focus groups were conducted with respect to the emergent design.

It was important to over-recruit (Morgan, 1988; 1993) in order to allow for absences. The initial eleven interested women were provided an on-reservation contact person at the clinic (the Public Health Nurse) and an off-reservation contact person (the researcher) at Portland State University.

\section{Focus Group I}

Nine women maintained an interest in participating in the dissertation study and yet, only four women showed up for the first group. The reasons for not attending are not known although the lack of transportation and geographical isolation common to reservation communities is a consideration. These factors are 
limitations for women that planned to attend meetings scheduled during the work week. In the ROMPP study (1995a), IHS clinic vans were used for transportation of participants.

\section{Focus Group II}

In recruiting for the second focus group, women from the remaining 16 on the referral list were considered. After consulting with the tribal community health representative about limiting the participants to those who were unemployed and not in administrative positions, ten women were re-contacted by telephone for the second time. Eight expressed interest in participating. Materials were re-faxed to the respondents, yet only three participated in the second group.

The reasons given by the two women who chose not to participate were a schedule conflict or the lack of transportation. If transportation had been available, as in the ROMPP study (1995a), the group may have had higher participation and more diverse characteristics.

Before the focus group began, each participant signed informed consent forms agreeing to be interviewed, audio and videotaped. Formal statements confirming anonymity and confidentiality and a brief explanation about the previous ROMPP study findings in regard to the purpose for this study were given. (See Appendix B for Recruitment Pamphlet with Confidentiality Statement.) 
Participants were told that the study's aim was to inform health professionals about the reasons that, in some situations, Native American women chose not to use contemporary Western prenatal health care. The participants were also informed that assumptions of this research are that answers lay with those who have experienced changing cultural health beliefs about pregnancy and childbirth and the affects of federal assimilation policy; and that the role of the researcher is to explore the patterns in the intergenerational transmission of health beliefs among Native American women as a way of developing strategies to enhance the use of prenatal health care. See Appendix B for Statement of Purpose provided to the participants.

\section{Confirmatory Interviews}

Individual follow-up interviews were conducted by the researcher with each of the women $(\underline{N}=7)$, either by telephone or in person to substantiate themes and to gain participants' additional input and for the purpose of member checking which will be discussed later in the Trustworthiness section.

\section{Participants}

The actual sample size was determined by the nature of the data collected as a whole. Because of the large volume of verbal data, sample sizes remained small. The target generation of Native American women were born between 1932 and 1960. These years were concurrent with major federal assimilation policies 
including removal and relocation policies, ongoing federal Indian boarding school policy, and recruitment/conversion to Christianity.

The women in the dissertation study $(\underline{N}=7)$, therefore, were selected by discriminate sampling that chooses persons to optimize opportunities for verifying the relationship between categories and from what we knew from the ROMPP study and pilot work (1995a; 1995b).

They were most similar in their self-reported tribal affiliation, current age, participation in federal assimilation policy, experience with temporary relocation off-reservation, use of their native language, and residency on- or near-reservation.

Non-administrative work histories and family incomes of less than $\$ 10,000$ were criteria chosen in recruiting the second focus group to ensure representativeness that would not limit the findings and emerging theory to Indian women with administrative work histories or with family incomes of more than $\$ 25,000 /$ year, or both. This was because the range of occupations in the first sample $(\underline{n}=4)$ were self-identified as mostly coming from administrative work histories (two administrators, a community health representative, and a homemaker) and with only one participant with a family income of less than $\$ 10,000 /$ year.

Therefore, Focus Group $2(\underline{\underline{n}}=3)$ consisted of non-administrative participants (a health care provider, a community services worker, and a 
homemaker) and although one had a family income of less than $\$ 10,000 /$ year, two reported family incomes of over $\$ 25,000 /$ year. This leads to the assumption that the groups in this dissertation study remained homogenous, although allowances were made to recruit individuals from different work histories and income.

They differed minimally by yearly family income, number of children, and number of grandchildren (see Findings in Chapter Four). Other specific descriptive data will be found in Chapter Four section.

\section{Data Collection}

Interviews were conducted in the IHS tribal conference room, a setting convenient and familiar to the participants, in private, where they felt comfortable and safe. The natural setting was utilized with the realization that the context is taken into consideration as a part of the whole, rather than in isolation.

\section{Profile Questionnaire}

A self-report questionnaire was completed by participants prior to conducting the focus group interviews. (See Appendix C.) The questionnaire was designed to gather descriptive data to provide an accurate sense of who participated, including: demographic descriptors (e.g., age, marital status); tribal affiliation; socioeconomic information (e.g., education, employment, income); child(ren)'s ages; cultural experiences; and assimilation experiences (e.g., relocation, boarding school, and so on). 


\section{Ethnic, Cultural, and Religion/Spirituality (ECR)}

The questionnaire was administered with the Profile Questionnaire at the beginning of the focus group. Family resiliency has been defined as how families adapt to stress and bounce back from adversity (Hawley \& DeHaan, 1995). The Resiliency Model of Family Adjustment and Adaptation (McCubbin, McCubbin, Thompson, \& Thompson, 1995) proposes that family dysfunction is mediated by a family appraisal process involving the family schema, the family sense of coherence, the family's resources, family hardiness, social support, and family problem solving and communication. Researchers have only recently begun to explore culture and ethnicity as integral and contributing factors to family resiliency in responding to and coping with stress and crisis (Cross, 1995; McCubbin et al., 1995).

The construct of resiliency appears to be a meaningful protective factor and useful in understanding Native American family systems. Zimmerman, Ramirez, Washienko, Walter, and Dyer (1995) suggest a theoretical framework that focuses on strengths rather than on problems and on social norms and values of a minority group, rather than on comparisons with mainstream society. In this way, knowledge about how culture may influence health is advanced rather than differences between groups simply described. 
The Ethnic, Culture, and Religion/Spirituality (ECR) questionnaire (Cross, 1995) gives a framework for understanding resilient behavior. Cross (1995) proposes natural healing qualities of family life and gives a framework for understanding resilient behavior. It hypothesizes that the system's natural tendency is toward harmony and thereby, resiliency. The ECR scale is designed to measure levels of identification and involvement with Native American culture based on a relational rather than a linear world view. In the Native American relational view, the problem is viewed as circumstantial and residing in the relationship between or among various factors.

This dissertation study provides descriptive evidence about culture as a contributing factor in Native American resiliency. Cultural factors were identified that were believed to contribute to resiliency among Native American women. The ECR scale was used as a way to examine identification with culture, native language, participation in community and cultural activities, and utilization of community and cultural resources. Realizing the limited numbers $(\underline{N}=7)$, the aim was only to measure whether participants did or did not identify and utilize cultural systems and as a way to demonstrate self-identification with Native American resiliency factors.

The ECR self-report measure was completed by participants at the beginning of the focus groups. The numerical responses for the nine questions 
varied. For example, responses for questions 1-6 were coded 0-4 with "not applicable" at 0 and "a lot" at 4 ; question 7 is a dichotomous choice ( 0 "no" or 1 "yes"); and responses for questions 8 and 9 vere coded $0-3$. The maximum score possible is 39. (See Appendix C.)

\section{Social Integration Continuum}

May's (1982) social integration continuum describes four types of cultural adaptation which contemporary Indian women make that reflect on susceptibility to negative coping behavior such as substance abuse. Factors of identification with culture (including traditional, modern, both, or neither) were used to describe the women in the study as follows.

\section{Traditional Factor}

This susceptibility scheme proposes that Indian tribes and cultural groups have been found to be at high or low risk for many types of deviance because of their tribal customs which encourage or discourage these behaviors. Tribes which have a more rigid and fixed social structure are much more prone to enforce conformity and less likely to produce deviance. Among examples of this type of tribe were Northwest Coastal Indians (May, 1982). In this manner, susceptibility or resistance to alcohol problems, suicide, crime, and so on, are couched within traditional social organization. 


\section{Modern Factor}

Social disorganization, cultural and social change, cultural conflict, and resulting interpersonal stress have been cited as influential in producing deviant behavior (May, 1982). Using this scheme, tribes undergoing rapid social and cultural change by modernization will produce higher levels of deviance (May, 1982). Studies have linked these changes to depression, school failure, alcoholism, suicide and other escapist behaviors (Bryde, 1970; May, 1982). Evaluation and explanation of patterns of alcohol abuse and other problem behaviors are possible under this scheme. Please see the following excerpt:

Tribes with loose social organization would be expected to have the highest rates of drug abuse while those with tight or high levels of organization would have the lowest rates ... tribes undergoing forced and rapid change, whether overt or subtle, will also experience higher rates of drug abuse than tribes in relative isolation from these problems (May, 1982, p. 1200).

Susceptibility of an individual can be judged based on the individual and his/her family's social adaptation (May, 1982). Based on this scheme, adjustment to traditional Indian values and also to modern, mainstream values will reflect on 
their likelihood of substance use or other problem behavior. Following are May's (1982) categories of individual social adaptation.

\section{Adapted to Both Cultures}

If an individual and his/her family are well integrated socially and perceptually with both Indian and modem society, they are the lowest risk for negative coping behavior (May, 1982). These people have a dual source of identity.

\section{Adapted to Either Culture}

Closely related in terms of susceptibility are people who are well integrated to traditional Indian society and therefore, less likely to respond with negative coping behavior (May, 1982). The same might be said for Indians highly integrated into modern, non-Indian culture. Thus, those with a strong integration or attachment to either modern or Indian society are at low risk, but not as low as those integrated within both cultures.

\section{Adapted to Neither Culture}

Finally, it is suggested that those most susceptible to respond with negative coping behavior are those who are not integrated into either traditional or modem society via their family orientation or their own achievements (May, 1982). Therefore, May's (1982) schema is an example of how tribal structure, 
modernization and rapid change, traditional and modern integration affect individual responses.

\section{Focus Groups}

Focus groups interviews were chosen as a time- and cost-efficient approach to data collection (Lincoln \& Guba, 1985). These interviews offered the opportunity to gather rich data about the reality of Native American women's lives by gaining information about their experiences.

The focus group interview schedule (see Appendix C) about the pathways to exchange pregnancy and childbirth beliefs and practices was designed to gather data from key participants and added to ROMPP findings and pilot work (1995a, 1995b). The selection of the subsequent focus group members was made to confirm findings and emerging themes and to identify other relevant information for further consideration.

Member checking was conducted with each participant, negotiating the facts and interpretations with the researcher. This was ongoing throughout the interview process. The inquirer attended to participants' views and honored them as far as possible.

\section{Data Analysis Framework}

Qualitative data are interpreted to understand what was found in a particular context, for that time, and in a holistic way. In qualitative analysis, meaning 
cannot be attained for a whole by simply looking at its parts, therefore, inductive data analysis was the process for making sense of data (Lincoln \& Guba, 1985).

The investigator utilized the dissertation research as a way to elaborate and confirm interpretations suggested in the ROMPP study and pilot work about the transmission of cultural health beliefs and practices regarding pregnancy and childbirth. Major themes from the ROMPP study and pilot work (1995a; 1995b) were used to guide the study but themes continued to emerge and themes continued to be modified to reflect the data.

However, data were not forced or selected into pre-conceived or preexistent categories. Most categories of grounded theory are generated directly from the data, (Glaser, 1978) but this does not mean that all categories emerge from the data alone. Categories in the literature might apply (Glaser, 1978). The concern, naturally, is not to contaminate one's effort to generate concepts "from the data with preconceived concepts that may not really fit, work or be relevant, but appear so momentarily" (Glaser, 1978, p. 31).

In this dissertation study, criteria for theoretical saturation were considered through ongoing peer debriefing activities. Saturation of categories refers to completeness and occurs when all the data fit into the established categories and no new data emerge to indicate new codes or the expansion of existing ones (Glaser \& Strauss, 1967). At the saturation point, the researcher knew her categories quite 
well and could not be persuaded from them or even to sharpen them unless they were better, not just merely catchy phrases (Glaser, 1978).

Emerging hypotheses were constantly reconstructed by ongoing analysis of data by constant comparative methods (Glaser \& Strauss, 1967) by identifying and describing concepts, and by negotiation of themes with the subjects to discover underlying interactive processes and a core variable essential for emergent theory.

\section{Process of Analysis}

The process of analysis began with initial data generation and continued throughout the research. As data were generated, categories emerged and a tentative conceptual framework developed, using key processes of substantive coding, substantive categorizing, and constant comparison.

The Ethnograph computerized data management system (Seidel, 1995) was used for development of a log of analysis operations such as code constructions and searches and retrievals, maintaining the audit trail. Documents such as the code books and memos (coding notes) were the working products compiled by this system. The computer program was used by the researcher to enter the transcription of videotaped interviews, field notes, journals, and observations for management and analysis of qualitative data. 
A system of substantive coding including all data examined line-by-line was used to identify what the participants said. Coding was based only on the data to prevent the imposition of preconceived impressions, and as many substantive codes as possible were used to insure full coverage. Decision rules were used by the researcher to input data into categories. For example, a theme was coded by the researcher as present for an informant if mentioned repeatedly or with strong affect, or if it was mentioned and/or confirmed by more than one respondent during the group interview (see Table 4).

Table 4

Chart of Constant Comparison

$$
\text { Phase I - Analysis }{ }^{1}
$$

- Data collected and converted into Ethnograph program by numbered printed data.

- Data coded, reviewed, modified; coding book developed.

- Member checking with participants.

- Organized into domains of larger units.

- Theoretical sampling of literature in support of emergent themes.

- Expanded and/or modified categories incorporating emergent ideas and focus by constant comparative methods. 


$$
\text { II - Trustworthiness }{ }^{2}
$$

- Peer debriefer provided a reliability check to ensure intercoder reliability by independently coding $10 \%$ of data (produced approximately $98 \%$ agreement).

- Peer debriefer provide external check on interpretation by sampling analysis documents and exploring biases.

- Modifications were made as necessary.

- Audit check conducted by outside colleague to ensure consistency of coding. III - Theory Building ${ }^{2}$

- Integrated categories that took on attributes of explanatory theory; matrices developed.

- Theoretical sampling of literature to support emergent categories and matrices.

- Categories became saturated; construct developed and nesting of concepts; refined set of hypotheses.

- Causal mapping/theoretical model developed.

${ }^{1}$ Applies to Focus Groups 1 and $2 ;{ }^{2}$ Applies to Theory-Building Process.

Following completion of the first focus group interview, analysis began by identifying initial themes from the taped interviews. Actual coding was delayed until transcriptions were possible on the newest version of Ethnograph. Analysis 
followed processes described by Miles and Huberman (1994) utilizing the constant comparative method (Glaser \& Strauss, 1967).

Theoretical coding was enhanced by theoretical sensitivity (Glaser, 1978). That is, the more theoretically sensitive the researcher is to class, gender, race, power, and the like, the more attentive she is to these matters. The procedures of theoretical sampling and constant comparison are allied with theoretical sensitivity. For example, in this study, the literature reviewed provided for theoretical coding, theoretical sensitivity and research direction by increasing awareness of the socioeconomic, cultural, and historical/political factors in Native American life.

Although the category codes were abstract, patterns began to take shape. Data were compared for similarities and differences in the experiences of women interviewed and observed. Memoing of reasons was done when determining alternative coding and when recoding substantive data and categories.

In the first transcription (Focus Group I), the codes were compiled under a general domain associated with pregnancy and childbirth such as past and present experiences, cultural and contemporary health beliefs and practices, traditional pathways, ways information is shared, experiences with Indian policies and institutions, and ways families dealt with assimilation policies.

The second transcription (Focus Group II) was analyzed by using existing codes and by creating new codes as they were needed. Categories were constantly 
reviewed, refined, recoded, or combined whenever possible for better fit in order to capture the meaning of a certain set of codes. Analysis of the second set of transcriptions and of member checking transcripts occurred much more consistently by referring back and forth between the original categories and revised categories in order not to misrepresent data taken out of context. The researcher constantly questioned the data.

\section{Common Themes}

Matrices were constructed during later stages of analysis for the purpose of identifying patterns and themes. Nesting of concepts within higher level categories emerged from various groupings of nested concepts. An example of lower level concepts such as experiences of "cultural insensitivity" "health care providers," "nurses," "comfortable experiences," traditional roles," "tending children" were some concepts that became nested within subcategories of "traditional/Indian perspectives" and "contemporary modern perspectives" under the major overarching theme "balancing two worlds." When no further relationships were identified from the various groupings of nested concepts, analysis halted (Glaser \& Strauss, 1967).

All coding was conducted by the researcher. Review of the findings by two experts (peer debriefers) familiar with women's issues on the reservation was conducted in order to attest to interpretations from samples of the text transcribed, 
coded interviews, analysis records, emergent themes, coding lists, joumal, and other documentation within the audit trail to establish trustworthiness. (See letters attesting to trustworthiness in Appendix D).

In generating grounded theory, all data from all sources were analyzed. The constant comparative method of analysis was particularly important in handling data. Variations in data were not seen as tests of each other but as originating from different modes of knowing that needed to be explained and integrated theoretically, to enrich and densify the emerging theory, not to disprove it (Glaser \& Strauss, 1967). The resulting framework relies on symbolic interactionist theory (Glaser \& Strauss, 1967).

\section{Establishing Trustworthiness}

In qualitative inquiry, four elements parallel conventional criteria of internal validity, external validity, reliability, and objectivity. These are credibility, transferability, dependability, and confirmability (Guba \& Lincoln, 1994; Lincoln \& Guba, 1985). It is important in qualitative research to establish trustworthiness using these criteria.

\section{Credibility}

The aim was to carry out the inquiry so that the findings would be found to be credible. The following activities for increasing the probability that credible findings would be produced were undertaken: 
Triangulation (Lincoln \& Guba, 1985) involved using multiple methods of data collection to verify information gathered from these women. These included self-report questionnaires, a survey of cultural identification via the ECR instrument, two focus groups, and member-checking. Together these activities helped to ensure that data were credible and that the working hypotheses accurately describe the process of cultural transmission among these Native American women.

Peer debriefers were familiar with health issues of Native American women living on Indian reservations. They attested to interpretations by sampling the text of recorded interviews, analysis records, emergent themes and coding lists, journals, and other pertinent documentation. Both debriefers provided ongoing consultation and feedback throughout the study. Biases were explored with one peer prior to the study, and with the other peer, later in the process of data analysis. Data collection and analysis procedures were explored. In order to keep the researcher honest, the researcher's biases were probed, meanings explored, and the basis of interpretations was clarified through peer debriefing activities with the researcher. (See Appendix D for letters attesting to credibility.)

Member checks provided for the direct test of findings and interpretations with sources from the study. In this study, Focus Group 1 was held in July 1996 and member checks conducted in March 1997; Focus Group 2 was held in March 
1997 and followed up by individual telephone interviews in April 1997. Both focus groups were held to allow for emergent codes and themes. Follow-up interviews (member checks) confirmed major theme constructions and substantiated meanings.

\section{Transferability}

Grounded theory is not intended to be generalized (Lincoln \& Guba, 1985), therefore, the major responsibility was viewed as providing thick description that makes transferability judgments possible. The study sets out working hypotheses together with a description of the time and context in which they were found to hold and in this way, enables others to reach a conclusion as to whether transferability is possible to other communities of Native American women.

In this dissertation study, thick descriptions by Indian women provided rich information about the transmission of cultural beliefs and practices, the effects of federal Indian policy, loss of traditional roles among women, risk-generating responses, and cultural resiliency. Findings from this study are dependent on the time (transmission of culture and health beliefs between 1950 and 1990) and on the context (rural Oregon by a homogeneous group of Native American women, residing on the reservation, having experienced federal assimilation policy, temporarily residing off-reservation, and representing a tribal heritage in common). 


\section{Dependability}

A single dependability audit by a colleague was used to examine the process and attest to the data, findings, interpretations, and recommendations via the audit trail. A Nez Perce tribal woman, retired professional health care provider, and cultural leader, who is familiar with health issues for Native American women and lives on-reservation conducted the external audit. The audit trail included examination of raw data, transcribed data, data reduction, and analysis products (field notes, concepts, findings, final report, connections to existing literature, relationships, interpretations, process notes, preliminary and revised schedules, questionnaires, and journals). A letter attesting to the dependability of the researcher's findings is provided in Appendix D.

\section{Confirmability}

With the intention to establish that findings were generated by respondents and not by biases and motivations of the inquirer, the outside audit was also conducted by the external auditor. This single audit determined dependability, confirmability, and credibility simultaneously. This was enhanced by examination of the audit trail that includes logs that tracked activities, reflections, awareness of bias, and emerging hypotheses. This audit was attested to in Appendix D.

In summary, several measures to ensure the trustworthiness of the study were integrated into the design: (a) triangulation across data collection methods 
(focus groups, individual interviews, and questionnaires to establish credibility), (b) peer debriefing to provide for external checking, conducted with two colleagues familiar with Native American health and familiar with the ROMPP study (to establish credibility), (c) member checks, conducted with study participants, to substantiate findings (to establish credibility), (d) thick description for rich cultural interpretation within the context and the time focus groups were held (to establish transferability), and (e) an external audit of the researcher's data collection and analysis techniques by an independent source (to establish dependability and confirmability). These measures enabled the researcher to rest assured that everything had been done to make the study trustworthy and credible. 


\section{CHAPTER FOUR}

\section{FINDINGS LEADING TO THE FINAL HYPOTHESES}

This chapter describes the sample and context and then reviews the findings of the dissertation study. Then hypotheses are generated and the emergent explanatory model discussed in Chapter Five.

\section{Context of Sample}

To ensure confidentiality and anonymity of the Oregon tribe, all references to the specific tribe or bands are omitted from this study. The sixteen reservations in Oregon were created between 1853-1990. The transformation of Oregon Indians into sedentary, agricultural, English-speaking Christians was mandated by Bureau of Indian Affairs for a century between 1856 and 1956 (Beckham, 1991). The transformation and "civilizing" of Indian children was driven by boarding school policies that enforced a strict English-only policy. Each generation removed them farther from traditional family and tribal life.

The tribe in this study has a rich tribal heritage. Since this reservation was established over 100 years ago, the people have seen great hardship and loss of traditional culture and yet they have succeeded in holding onto many of their ancient traditions and values. Though this tribe was not directly impacted by removal policy, relocation policy's intent was also to promote assimilation by coaxing adaptation to the ways of a culture that was perceived as distant and 
irrelevant. Considering the low value placed on the tribal culture at that time, it is a wonder that the people retained any sense of identity at all (Beckham, 1991).

Tribal citizens benefit personally from certain rights reserved for them in their treaties and from subsequent interpretation of the government's "trust responsibility" for Indian tribes and lands. These rights and privileges are tribal, not individual, gained by virtue of membership in a federally recognized tribe (Stowell, 1987). These rights include access to public health care, educational opportunities, protected off-reservation hunting and fishing, and other privileges and services not available to non-Indian citizens. Monthly per capita payments and yearly bonuses are provided from tribal income in successful business ventures, not from government generosity.

Available health services to this reservation include one hospital, one nursing home, one home health agency, and two non-residential drug and alcohol treatment programs. The County Health Department provides public health services including a prenatal care clinic. Indian Health Services provides clinical services on the reservation including prenatal care and a maternity nurse who does home visits and case management.

\section{Study Participants}

The demographic descriptions of this particular group of Native American women were gathered by a self-report questionnaire. Realizing from pilot work 
that demographic information would provide a sense of who was participating, women were asked about their tribal affiliation, participation in cultural activities within the last year, yearly family income, last grade completed and levels of higher education/vocation, children('s) and grandchildren(s) name(s) and age(s). They were also asked to identify reasons for moving off-reservation, at what age they moved, and the number of years. Their reasons were associated with federal assimilation policy included: boarding school or relocation programs. Other possible reasons for moving due to relocation policies included moving to the urban areas for training, employment, and educational opportunities, with the parents or personally. Finally, they were asked for concerns that they had about prenatal care for young Indian women today. Biographic information on participants is in Table 5.

The study sample was composed of Native American mothers from three bands of a tribe in rural Oregon. To ensure anonymity and confidentiality of the participants, first names were replaced with Animal Creation names common to Native American legends: Bear, Coyote, Eagle, Fox, Owl, Salmon, and Wolf. These women were born between 1938 and 1957 during the era of World War II, the Korean and Vietnam Wars, who have come to be considered "baby boomers." They often became mothers in the 1960-1980s although one participant elected to give birth in 1996. These individuals' collective identity was shaped by the 
Table 5

Biographical Sketch of Women Participants

\begin{tabular}{|c|c|c|c|c|c|c|}
\hline $\begin{array}{l}\text { Focus } \\
\text { group } \\
\text { \# }\end{array}$ & $\begin{array}{l}\text { Age } \\
\text { group }\end{array}$ & $\begin{array}{l}\text { Marital } \\
\text { status }\end{array}$ & $\begin{array}{l}\text { Years of } \\
\text { education }\end{array}$ & $\begin{array}{l}\text { Range of } \\
\text { family } \\
\text { income }\end{array}$ & $\begin{array}{c}\# \\
\text { children }\end{array}$ & $\begin{array}{c}\# \\
\text { grand- } \\
\text { children }\end{array}$ \\
\hline 1 & +48 & Divorced & 14 & $\begin{array}{l}25,000- \\
40,000\end{array}$ & 2 & 4 \\
\hline 1 & -48 & Married & 12 & 10,000 & 5 & 1 \\
\hline 1 & +48 & Married & 12 & $\begin{array}{l}25,000- \\
40,000\end{array}$ & 6 & 10 \\
\hline 1 & -48 & Single & 19 & $>40,000$ & 1 & 0 \\
\hline 2 & +48 & Married & 12 & $>40,000$ & 6 & 3 \\
\hline 2 & +48 & Married & 16 & $\begin{array}{l}25,000- \\
40,000\end{array}$ & 3 & 3 \\
\hline 2 & +48 & Widowed & 11 & $\begin{array}{l}10,000- \\
25,000\end{array}$ & 3 & 4 \\
\hline
\end{tabular}

Korean War, McCarthyism, the emergence of the civil rights movement and the Vietnam War.

During this time, in 1953, under the auspices of addressing the "Indian problem," thousands of Native American families were "relocated" to urban areas to assimilate into mainstream society. This generation was also affected by forced 
assimilation policies in 1954 that resulted in termination of Indian tribes in Oregon destroying entire tribal communities and families and their traditional value and belief systems. Starting in 1953, an Indian could, for the first time in his or her lifetime, drink legally when federal Indian prohibition was repealed. This tribe chose not to legalize the sale of alcohol on-reservation until 1971. Some reservations still prohibit alcohol use on reservation.

\section{Case Studies: The Middle Generation}

By videotaping these focus groups, I was able to closely observe the interactive process, while being part of it. In the videos I looked for body language, periods of silence or drawn out periods of contemplation, cultural beliefs and practices, and also for things that were missed that could be picked up by "technological peripheral vision". I reviewed the tapes almost immediately after each session and took notes. Transcription was done later and was a much longer process.

Substantively, smaller groups demanded a greater contribution from each individual participant. The women in both groups were relaxed, comfortable, and familiar with each other, and with me. I suspect that being an Indian woman with a common history, age, and from a local reservation was advantageous. Also, we had individually met and discussed the study over the telephone, by fax, and by mail, several times before the initial session. All women had attended boarding 
school or experienced relocation policy in some way and therefore, they had relocated off-reservation, temporarily. This relocation experience was either with their families or by themselves.

Bear had experienced pervasive cultural, social, and political change over time on the reservation. She had grown up in a very strict, traditional family of respected tribal leadership. She also experienced as a child and young woman, the tragedy of boarding schools and relocation programs and she articulated it well in her sadness and feelings of isolation as a child. She continues to speak her native language. Her career started in clerical positions and she has successfully entered into administration. She was divorced and working through the adjustment phase, but remains very active in extracurricular community activities that address women's issues. As a grandmother, she continues to be actively involved with her grown children and their families. She is a member of the Shaker and 7-Drum Indian religions. She also involves herself in a second career in Native medicines and reported that she became enchanted with the possibilities of alternative medicine during the past year when she was faced with the reality of her son's diagnosis of cancer. She was warm, respectful, and very spiritual. She gave me a hug in parting.

Owl doesn't consider herself an elder, although she teaches culture to other young women if they're interested. She grew up in the 1940-50s at a time when 
being "Indian" was of little value. Memories of her childhood and her mother were from a place one reaches after coming to peace with one's own shortcomings and has forgiven, but not forgotten. In her mind, her parents had done the best they could do under the grueling circumstances that they had and this seemed to comfort her. She married a military man and was separated from her tribe and family for years and therefore, experienced pregnancy and childbirth away from home and family. Owl seemed wise in her own gracious eloquence. She had attended some college, but doesn't work. She is family-oriented with children ranging in age from their thirties to a teenager. She also hugged me at parting.

Salmon was raised by her widowed father and elder family members. She also speaks her native language and clearly remembers her traditions and beliefs. Her stories of boarding school and as a young mother and a victim of spousal abuse are memorable and very sad. Yet, she has come to terms with her past and has moved on. She spent less than a year off-reservation for training or other educational reasons. She participates in the Long House religion, has grandchildren, and is remarried and still does not work outside the home. She was spontaneous in her responses and was often the first to use humor to break the edge of silence. She was comfortable to be around and seemed to listen intently and respectfully to what each person had to say. She also hugged me at leaving. 
Wolf recently became a mother. She was actively involved in tribal politics gained from her own family's political background. Her mother was also collegeeducated before she married. Her dad relocated his young family to a city for nearly three years to complete his college education. Although she didn't attend federal Indian boarding schools, she did attend private, parochial schools, and therefore, lost much of her early cultural training. Her mother was not from this reservation and was considered a "modern" woman for her time. Therefore, she gained much of her cultural wisdom from her paternal grandmother. She resided off-reservation for more than six years attending school. She worked on the reservation after college, but returned to complete law school. She now works in administration and management for the tribe. She was the only one from either group that did not speak her native language, but attends most of the yearly cultural events and admits that the trade-off in cultural wisdom was made up in educational wisdom and feels that there is a balance. She says that there is much that she doesn't understand about cultural issues that she is learning along with her infant son. She was warm, open, and gracious.

Coyote fondly remembered her grandmother and was the only one in her family to "stay married to the same man" and she bases this choice on her grandmother's advice to "stay with him, no matter what." She recognized changes in today's world but doesn't agree with much of it and remains faithful to most of 
her grandmother's advice. She lived off-reservation for less than three years for jobs, training or education in her 20 s and 30 s. She is actively involved with the Long House religion, speaks her Indian language and attends some cultural activities during the year. Today, her grown sons and grandchildren are the focus of her attention, although she is a busy professional women in the health care system. She was very jolly, laughing and joking often, and was enthusiastic in her responses to the questions, but became very quiet during the last part of the discussion although she rejoined the group at the end.

Fox grew up in a very traditional tribal lifestyle with an elder grandmother who taught her many traditions and practices that she shares within her own family. She had worked at the Indian health clinic as a community health representative for some years and enjoys working in maternal and infant child care with the nurses and physicians. She had just been accepted into college and was anxiously awaiting to begin classes next year. She was married to a non-tribal member and was fast-paced and eager to share information. As a staunch supporter of cultural events in the community, she enjoys teaching culture to young women, and knows "a little Indian and some Spanish".

Eagle is recognized by the community as a spiritual elder. She belongs to the Indian Shaker religion and speaks her native language. Her family keeps her busy. She works with the tribal children's social services and is involved in the 
community. She was thoughtful in her responses and when she spoke, she was allowed time (by the group) to think and articulate her answers. She shared stories of boarding school, the meaning that children have in families, and the traditional "way of life." She was very helpful to me in understanding about culture and stayed after the others left to make sure I understood. She also hugged me when she left.

\section{Section Summary}

Interviews indicated homogeneity among the two groups. All participants were mothers, resided on-reservation, were enrolled tribal members, (although representing diverse bands), had participated in federal assimilation programs, and had participated in some type of cultural activity in the last year (mostly powwows). As of March, 1997, their average age was 49.7 years old; range was 39 to 58 years; four were married, one was divorced, one had been widowed and one had never married. Most of the participants were grandmothers (6 out of 7). All but one of the participants spoke their native language, although not fluently. One family income was less than $\$ 10,000$ per year. The median range of family income was $\$ 25-40,000$ per year. Two respondents reported family incomes of more than $\$ 40,000$ per year. All but one had graduated from high school; three had attended some college. 
Five out of 7 women had three or more children; children's ages ranged between 11 months to 39 years old. The number of grandchildren ranged from 0-10 and ages ranged between 3 months to 13 years old. Only one informant had relocated off-reservation due to military assignment with a spouse. Three had attended federal boarding school (beginning age ranged from 6 to 15 years old), and one had attended parochial boarding school through high school. One had formally participated in a relocation program to an urban city at the age of 20 years old. Two respondents had relocated off-reservation for job opportunities, both at age 21 years old; and three others had relocated for their own education or for their family of origin's training and/or education. Only one participant lived offreservation for more than three years.

\section{Findings}

Connections among the major themes are explored in this section. These themes emerged from thick description and led to hypotheses and emergent theoretical frameworks. Focus group questions 1-6 were about experiences of the transmission of cultural health beliefs and practices, ways that information were gained, ways that women shared information, differences in the ways information were shared among women today, ways that their families were affected by federal assimilation policies, and ways that families dealt with these policies (see Table 6). Common themes categorized their responses (protective and risk-generating) 
Table 6

Focus Group Questions

Question

1. Thinking back when you were pregnant and had your first baby, what comes to mind? Think of how it is now different.

Probes: Was it easier/harder than it is now in terms of beliefs or practices.

2. What are some of the ways in which you gained information about pregnancy and having babies?

Probes: Sweat Lodge, mothers, grandmothers, family, health care providers, reading materials.

3. What are ways in which information was shared among children(ren)/family about pregnancy and having babies:

Probes: Cultural ways; contemporary ways.

4. What are the differences between the ways in which young mothers today learn about pregnancy and having babies and the ways mothers learned about pregnancy and childbirth when you were pregnant and having babies? Can you think of ways to make it better?

Probes: Sweat Lodge, grandparents, prenatal care, PHN; suggestions to make it better. 
Question

5. One of the things we know by talking to young mothers and elders is that it is hard to separate ourselves from federal policy and programs because it affects what we do every day. Thinking back again to when you were growing up, how did the policies affect cultural beliefs and activities for you then?

Probes: Relocation, boarding schools, removing children; language, pow wows, cultural ceremonies and activities.

6. Thinking back to when you were growing up, until you were pregnant, can you describe ways of coping that were used by you and your family in dealing with federal assimilation policies?

Probes: Resiliency of extended families, oral history, wisdom of elders, going underground. Others: substance use, violence (spousal and so on).

7. Can a theory be developed to explain or clarify the meaning of the transmission of cultural beliefs and practices about pregnancy and childbirth and variables among Indian women that serve to facilitate or impede access to prenatal care? 
associated with the breakdown in traditional pathways concerning cultural health beliefs and practices.

This culmination is based on plausible relationships between sets of concepts that are grounded in the data. A substantive theory explains or clarifies the process of intergenerational transmission of cultural health beliefs among Indian women associated with prenatal health choices is described.

The researcher discovered that factors in the process of transmission of cultural health beliefs could be clustered into three sets of categories: Federal assimilation policies, consequences of assimilation policy, and ways of responding. These sets, or units of activities or situations, were not mutually exclusive and were continually interacting.

Behavioral reaction to federal assimilation policy and consequences of acculturation/adaptation associated with culture-affirming and risk-generating elements became the cultural pathway used by women in response to repeated experiences and conditions.

\section{Federal Assimilation Policies}

The women described experiences of Indian boarding school and relocation policy and ways that families dealt with these policies. Owl remembered that historically, tribal ways were inclusive of "one big family." 
The tribes were interdependent of each other and had a strong sense of family and responsibility for each other. But as time went on we became more dependent on the government... we are now struggling with being independent of Indian Health Services and the Bureau of Indian Affairs.

Each participant communicated ways that federal assimilation policy had disrupted their cultural lifestyles in unique ways.

\section{Indian Boarding School}

Owl, the oldest participant, remembers a Bureau of Indian Affairs day school that was part of the boarding school that was located on her reservation. (Her mother, also a product of boarding school, worked as a school matron.)

They'd ring a bell and we'd line up and march to the classroom ... the purpose of boarding school was to teach Indian children a different way of living, a better way of living, to break the family up, and it did that. The kids stayed out of the home. I know that because my mom was a matron and she was a product of the boarding school.

Eagle shared memories of separation from her parents, being punished for speaking her language, and taking care of younger, newer Indian students: 
Indian language was removed from us, [language] which I still understand, but I don't speak it fluently anymore. . . it was really hard. I remember being taken to boarding school and left, seeing my folks about three months out of the year. After the first couple of years you don't speak the language anymore, and you hurt for the newcomers, especially when they are very little. That's the only language they know and you know they don't understand and you try to help them, and you get punished. . . I remember standing in the hall a lot as punishment.

Bear remembered her grandmother preparing her for boarding school, "They'll change you everywhere-cut your hair, change the way you dress and your language, but they cannot change the color of your skin or in here [pointing to her heart]."

Shared memories of boarding school were that it was a traumatic, lonely experience of rigid discipline. Rules created a formalized regimen that began early in the morning, with lining up in the hallway, being referred to by a number rather than by name, dressing in uniforms, performing daily chores, attending school, forever marching, and eating a diet that excluded traditional foods of fish and other native staples such as eel, fry bread, venison stew, huckleberries, and elk. "We couldn't eat our foods at school, and therefore the diet changed." Group members 
shared often humbling experiences of memories of lengths of time separated from families and tribal culture, without anyone to talk to about personal health-related subjects, such as menstruation and pregnancy.

Salmon also remembered the effects of boarding school as being traumatic. She remembered how she learned, at a very early age, to adapt to the non-Indian world:

... being left by your parents and not knowing when they were coming back ... you were prouder now than you were then, because you were more torn knowing that you're Indian and knowing that you must learn to live in the white man's world. All the things you learn in boarding school are not that you learned at home, like fishing eels . . for me in the beginning, it was really traumatic, but then I think you learn to adjust, to get by.

Fox, a community health representative, had only attended boarding school during high school, later than Bear, in the 1970s. Boarding schools remained institutions, but under the auspices of newer policies, the infrastructure relaxed their rigidity and encompassed tribal planning. Her experiences at boarding school emphasized the "[influences from the] modern world taught me how to drink alcohol and smoke cigarettes." 


\section{Relocation Policy}

Wolf remembered, as part of relocation, in the 1950s that she moved with her family to a larger city for her father's college education. Her mother had already completed college before marriage. Later in the 1970s Wolf also attended graduate school and law school before returning to the reservation. She recalled three generations of family involvement with tribal politics and leadership "so we knew what was going on." She shared memories of tribal council members coming to her grandparents' house talking about "termination (policy) and what a terrible thing it was, and the awareness to the government trying to buy us off."

Owl also recalled the relocation period not only removing Indians from the reservation, but also bringing people from other areas to the reservation: "Relocation was meant to assimilate us into mainstream society but it ended up that most of the people that relocated came back to the reservation usually with mates and with children from other tribes or cultures."

Bear, raised in a traditional family involved in tribal politics, remembered that she was curious and wanted to learn about "the outside world." The reservation life offered little more than did a small town. It did not have a large, diverse population, theaters, fast food restaurants, laundry-mats, buses, or taxis. Bear participated in the relocation program in the early 1960s and moved by 
herself into an urban metropolitan area for office management training, again separating herself from her family and culture:

I learned how to catch a city bus and get around and live on my own ... you learn how the real world is, how to protect yourself, about cunning and manipulative people and you're scared ... but I returned to work for the tribe.

Most of the women became pregnant with their first children in the $1960 \mathrm{~s}$ and 1970s, although Wolf with many years of education, made a choice not to conceive until later.

\section{Discovery}

Six of the seven participants recalled experiences associated with Indian boarding school from an early age and provided rich descriptions of the profound experiences of boarding school in the eyes of Native American women. Although only one talked specifically about being a second generation boarding school student, experiences were similar and devastating to family and cultural systems and traumatic to young children. Parents, grandmothers, and older students had important roles in preparing young Indian children to leave and teaching them how to adapt. 
Experiences with boarding schools before the 1970s were very different than after. That would be expected with policies that changed the focus and direction of Indian education. For example, the 1975 Indian Self-Determination and Education Assistance Act provided for tribes to contract to run education and health programs and also provided more Indian control of schools and education of Indian children.

In the 1950-1960s, memories were framed around participating in federal relocation programs that removed Indians from the reservation couched in apprehension of what the modern, new, world would hold. The differences that were discussed may not be unlike "culture-shock" faced in reverse for city folks that would visit a small town or reservation at the same time. And, during this time frame, in the 1950s, Indians were just recognized as U.S. citizens and were allowed to legally drink alcohol. The implications are great.

Indian women living on the reservation rely on Indian Health Services for basic health services and health services were seen as improving. However, several voiced concerns about the relationship between IHS physicians, their relatively short time spent on the reservation, and their relationship with the government.

Bear shared concerns about the IHS educational pay back system: "Physicians [are required to] work at Indian Health Service clinics to return [pay 
back] years of [educational costs] service and, therefore, may not be here [in the tribal community] for the reasons to benefit the [tribal] people." This system doesn't promote physician-patient relations and fosters mistrust of physicians.

Another system barrier recognized by participants was severe "cutbacks in health care budgets that result in releasing clients prematurely." Services at IHS are said to be driven "by crisis rather than prevention-oriented." Comments by this group encouraged IHS to gain input from the Indian community for planning services that would be prevention-oriented and target issues of concern by young pregnant Indian women and their families.

\section{Consequences Of Assimilation Policy}

\section{Levels of Acculturation}

Acculturation refers to having taken on, or accepted to some degree, the values, life-style, or customs of mainstream non-Indian society (Choney et al., 1995). In this dissertation study each woman was identified by level of cultural integration by May's (1982) social integration schema. This model translates social integration and cultural adaptation by Indian individuals and their families into levels of susceptibility to risk-generating behavior. This allows description of each woman's susceptibility to negative coping behavior, primarily substance abuse, based on their individual and family's adjustment to cultural paradigms. 
The model was described in the instrument section and is considered to be a logical framework for this dissertation study to link the association between acculturation, adaptation, and risk-generating responses. All seven women had adapted to both (Indian and Modern) world views. These individuals were considered to be well-integrated/attached members of both cultures, having a dual source of identity, and lowest risk for negative behavior (May, 1982) based on interviews and data analysis.

\section{Loss of Language and Self-Identity}

A major stress associated with forced acculturation was the loss of native language. For example, Wolf, with a law degree, realized in the trade-off for education that there were a lot of things she needed to learn about cultural ways, such as language, that she missed in her earlier days when she was away from the reservation at school. Salmon, recalled memories of her mother's adaptation to a new culture that resulted in leaving her traditional old ways, including language, behind: "My mom, as I can remember, said we were not going to learn our language because we were getting ready for the white man's world. She spoke our language all the time to her sisters, but never spoke to us in our language."

The women indicated that during the 1940s to the 1960s being "Indian" was not valued, resulting in threats to personal integrity and loss of self-identity. This 
was associated with the breakdown in traditional cultural pathways shared among Indian women.

Owl remembered her mother sharing tragic memories of being institutionalized by spending most of her life in a boarding school until marriage:

So her idea of a family was more institutionalized and she didn't have traditional or cultural skills, even though she was an enrolled [tribal] member. We were born and raised on the reservation, but what we did get was what we got from dad's mom, but mom had nothing from her reservation and she was the way the boarding school raised her.

Memories centered around adaptation/ acculturation, loss of language and identity, and loss of traditional roles during a time in history when "being Indian" was not valued. Their parents were also caught between two worlds. By acquiescence to the modern world, they left behind the familiar. And, to protect their children and help them adjust to the changing world, they didn't pass down culture such as native language. This trade-off in cultures was pervasive:

My mom couldn't speak English when she went into boarding school, but when she left, she could barely speak her Indian language. My dad, on the 
other hand, was raised with his language and because mom and dad lived in an era when it was not good to be Indian, they didn't pass that down to their children.

Owl, remembering her mother, perceived that there were also those that truly lost their tribal heritage as a result of being separated from it for an extended time. Although, oftentimes, in appearance, there was a conscious "outside" appearance or acquiescence to acculturation:

... yet underneath, the core cultural belief was intact and strengthened for some, as they were re-exposed and re-grounded in visits home to the Reservation ... If you took her [mother] away from [her family] for a long time, something gets lost. My mom had little contact with her family of origin and it became more and more difficult as the years passed.

\section{Loss of Traditional Roles/Pathway}

Bear and Wolf both grew up in families involved in tribal politics and shared stories of family involvement in framing federal and tribal policies during the 1950 s and 1960s that historically impacted this reservation. It was recognized 
that federal policies had also disrupted traditional roles of Native American women.

Traditional roles of women had shifted as a consequence of acculturation. For example, women worked outside the home, extended family systems were split up into smaller units, children were sent away to boarding schools, or families were relocated to urban areas in the process of assimilation and acculturation. In this way, cultural beliefs and practices were not passed down among Indian women in the traditional manner because families were geographically and emotionally separated.

Owl perceived a major difference between her generation and that of her mother: accessibility to a traditional cultural pathway. She recounted experiences of reinitiating cultural and traditional connections: "After growing up and learning to reconnect with what Grandma taught us and regaining a strength out of that -- for example, the four of us [siblings] have Indian names."

Bear perceived that traditional family roles have been replaced by federal programs that promote dependency rather than interdependency. An example was seen in the way that the federal government intervenes before birth (prenatal care) and after death (funeral grants). An example of government intervention in death follows: 
[Preparations for a family member's wake and burial], that traditionally was all provided by the family ... we were taught that it was our family responsibility and not to rely on others to do that and is [valued] in the respect and honor for yourself and for the one that is deceased. . now that has changed in some cases, by the interference of federal programs and policies with little regard for cultural traditions. Some offer grants and have stepped in and taken over.

Local school systems nowadays are said to be taking the responsibility from the parents for providing sex education to young girls and it seems to work. However, participants felt that this type of education is left up to parents to followup at home, and this sometimes doesn't happen, therefore, parents need to be encouraged to take a more active role in their pre-teens' health education as well.

Bear also perceived that federal economic development programs and other outside influences in the 1950s destroyed family systems by breaking up families corresponding to a different paradigm that valued nuclear families and disregarded the sanctity of Native American extended family systems. "We had a lot of extended families here, living together in a household, and when [federal program] they came in, they really had an emphasis on splitting the family." 
These outside influences associated with acculturation have resulted in loss of traditional roles among women, especially transmitting cultural beliefs. A loss of traditional roles is seen as a critical factor in the breakdown of cultural transmission. Another consideration is levels of acculturation associated with a loss of traditional roles.

Discovery

Translating levels of susceptibility to risk behaviors in this model also includes adaptation to either or neither world view. Individuals with adaptation to either world view (Indian Traditional or Modern Western) have a strong integration or attachment to either society and are said to be at low risk, but not as low as those integrated into both cultures (May, 1982). Elders in the ROMPP Study (1995a) had strong attachment with the traditional Indian world view. Assumptions are that Indian women residing off-reservation with close ties with the Western world view would be identified as having a strong social attachment to the modern Western world view.

Those with attachment to neither world view were not expected to be integrated into either society (May, 1982), and considered to be without a culture. The younger group of Indian women in the ROMPP Study (1995a) would identify with a lack of attachment and of being "caught between two worlds" without a culture. 
The women commented about the impact of assimilation policy in devaluing their Indian-ness and considered this a major struggle and adjustment for them. Perhaps the feeling of insecurity and loss of identity as children would promote the adaptation process that these women eased into as young mothers. Yet, for some, acculturation, loss of language, identity, and roles didn't promote adaptation to the new, modern culture; it may have resulted in the contrary for some. The point is that Indian women in this study today feel pride and identify with their cultural heritage as a strength. They remembered that their parents' approach to the changing new world was to defer their cultural traditions, like language, and to make a break with culture and, in that way, to provide an opportunity for a better life for their children.

Historically, the traditional role of Native American women elders was to communicate and transmit cultural beliefs and practices to young women (Long et al., in review; Medicine, 1987). This study provides evidence that this traditional pathway to cultural beliefs with traditional elders has been disrupted by federal policies that discouraged cultural beliefs and practices and often resulted in loss of identity, feelings of oppression, and racism (Choney, et al., 1995).

The women discussed ways that traditional roles had been disrupted by assimilation policy and promoted dependency on the federal government. There remains an ongoing debate today about the pros and cons of the government-to- 
government relationship that exists between the federal government and individual sovereign tribal governments and its effects on Indian culture.

Bear recognized the importance of reviving the traditional pathway among Indian women by involving Indian elders with young pregnant women. Again, a reluctance by some Elders is apparent because some still feel that this cultural wisdom should be taught in their own homes and families. Bear noted that "If young people want to learn, they can come to the long house and learn things." The realization that there is a need for sharing cultural wisdom within the community in conjunction with established health care programs has been suggested in other studies (Long, et al,, in review,) and was expressed succinctly by Bear: "Some of the things we have learned have really had to be carried on from only what we can remember. Education and giving back to your community, that was really important to my parents for all of their kids."

\section{Ways to Respond}

Two major ways of coping responses used to deal with the breakdown in culture were discussed by participants. Following are examples of aspects that maintained culture through resilient family systems and that were protected by traditional women. Other examples that follow are of risk-generating responses that include substance abuse associated with family violence. Examples of health- 
enhancing aspects and stress-producing aspects of acculturation and ways they interact will be discussed.

\section{Coping Through Cultural Maintenance and Resiliency}

These participants perceived that federal assimilation programs of the 194050s removed families from the reservation at an enormous rate, but that they seemed to return to the reservation in droves. Often they brought with them spouses and children from different cultures. Wolf said: "The focus of relocation [policy] was to assimilate [Indians away from the reservation], but the way I was raised, this reservation was always my home, and that was where I would always come back."

Bear agreed: It's just one of those things, you're always going to come back sooner or later. I've spent a lot of time off the reservation, but this is always home.

Evidence from this study provides support for research that focuses on the maintenance and strength of culture as a means of overcoming social problems (Cross, 1995). Fox recognized that by growing up with her grandmother she had a rich cultural heritage that she values and shares within her extended family. "My elders taught me ... and that was my education. I took care of my nieces."

Owl remembers her grandmother, who spoke very little English, "taking care of us a lot, and we realized as we grew older that we probably understood [the 
language] more than we realized." Salmon remembered as a child that they "always had midwives that would come to the house. Wolf remembered that in the old days as a child in the 1940 and 1950s, "we didn't have electricity, water, or any of the modern things we have today, and people got along just fine, and we didn't have all these social problems." Bear acknowledged that the tribe now has a lot of social problems.

Federal assimilation policies aimed at destroying family belief systems by prohibiting native language and traditional practices were overcome by resilient Native American women who had learned to use the best of both worlds for themselves and their families. This study supports research that describes Native American women's dependence on oral history and stories as major vehicles to construct their meanings. For example, Bear remembers bits and pieces from her grandmother's oral traditional wisdom, that are not written down anywhere, about pregnancy and childbirth that she relies on today for teaching her own daughter and other young women about traditions:

And so some of the things that we have learned have really had to be carried on and from what we can remember. And sometimes, some of the elders are not willing to share things. They've kind of closed off and think that it should've been shared in your own household... What I try to do in my 
own life is I've had to pick what is the best for me from both sides. And I take the best for me; so I've attempted to do that with my own children.

Now I have a granddaughter and I feel like I am really open with her and not hide things from her so when she comes up against that, she can say, "oh yeah, I know about that already, and I have a choice.

Synthesizing the ECR instrument into the emergent study design was a minor adjustment and seen as a way to augment evidence of perceived sources of cultural support that build and promote the resiliency acknowledged in pilot work (ROMPP, 1995b) and other studies about resiliency among Native Americans (Long \& Nelson, in press).

In the dissertation study, all seven participants were proud of their cultural identity, and felt that it worked for them. Nearly all respondents spoke their native language $(\underline{n}=6)$. Participation in community activities and utilization of community resources were identified by most $(\underline{n}=6)$. These women individually are considered highly resilient because of their built-in support systems that evolved from pride and self-identity with their culture, familiarity with their language, participation in community activities, and knowledge and use of community resources. 


\section{Risk-Generating Responses: Substance Abuse and Family Violence}

Some stories are of family members who drank (alcohol) and the consequences to the babies and how these experiences helped change their choices. For example, Coyote reasoned that is why she chose not to drink and teaches her granddaughter that she also has a choice. Bear recalled, as a child, the devastation to the reservation when alcohol use became legalized in the 1950s. It was suggested by some participants that a generation will grow up without grandparents because of alcoholism and related health problems associated with acculturation. Recalling memories of Indian boarding school, she remembered the devastation to herself and to other Indian children in the loss of affection, acceptance, nurturance, and guidance from parents. She perceived that acculturation and the breakdown in extended family systems was responded to by some Indians with alcohol and drug abuse problems. "I have uncles that died of alcoholism and didn't know they were loved. There was no affection or bonding between parents and children."

Salmon's memories of the experience of being a victim of spousal abuse as a young mother were that options weren't available in the 1960-1980s. She sees substance abuse associated with domestic violence as the major concern for today's young pregnant Indian women and strongly supports education for young Indian women incorporated into prenatal classes. "Young women [should] know that they have options." 
Coyote recalled learning from her grandmother and now teaching her grandchildren:

I found myself sharing some of the things my grandmother told me about caring for myself like the drinking and smoking. It's a good thing that I was really respectful to my grandmother and I listened. She didn't tell me about alcohol syndrome but she told me "you don't drink" but then I also had this picture of family members who drank and seen some of the things that happened to them at a young age, like the drinking and leaving the babies in the cars, and getting into wrecks, and my heart went out to that child and made you mind. That's not what I wanted to do.

\section{Discovery}

Experiences with boarding school and relocation were identified by these women as resulting in cultural loss. Women were able to discuss their connection with the traditional "way of life," as a resiliency factor in times of stress during their life. These women's experiences are like those found in a literature review by Cross (1995) about strengths and cultural resilience in Native American women based on a core relational world view. 
These women were definitely concerned about the young women today and domestic violence associated with substance use. These women shared experiences about spousal substance abuse and domestic violence with feelings of isolation, desperation, and sadness they faced as young mothers. Similar stories of bravery were articulated in the ROMPP Study (1995a) about contemporary pregnant Indian women and their concerns about substance abuse and domestic violence during pregnancy. Among the challenges faced by reservation Indian women are how to address the domestic violence that threatens their unborn children's safety, as well as their own well being.

\section{Categories Leading to Theoretical Framework}

In this dissertation study the middle group of women, between 36 and 65 years old, were considered key informants to learn about the transmission of cultural health beliefs and practices about pregnancy and childbirth among Indian women.

Antecedent (preliminary) factors that influenced the breakdown in transmission were categorized under assimilation policies. Federal policies established Indian boarding schools and relocation programs in hopes of assimilating young Indian people into contemporary Western culture, and therefore, separated them from their traditional beliefs and cultural practices. The 
major consequence to tribal women was in "levels of acculturation, the loss of language and identity, and loss of traditional roles."

Two core elements used by Indian women to deal with the stress and assimilation were: (a) protective responses that included health enhancing aspects of cultural maintenance through resilient, extended families and tribal systems, and (b) risk-generating responses that included substance abuse and family violence. (See Figure 1 for categories and relationships of theoretical framework.)

Overarching Theme: Balancing Two Worlds

The three categories constituted the prevalent factors (causes, consequences, and ways of responding) that interacted in the process of transmission of culture. The overarching theme emerged as "balancing two worlds" and, thus, the way Indian women learned and shared cultural wisdom about pregnancy and childbirth. The overarching theme, "balancing two worlds" [views] emerged from the data. The two cultural world views emerged from discussions with participants who selfidentified more with the "traditional Indian" world and differed more from the "modern/contemporary" world category.

\section{Adaptation: Acculturation}

As young children in the 1940 s to 1960 s, these women perceived their mothers and themselves adjusting to the reality of learning "to live in two worlds." 

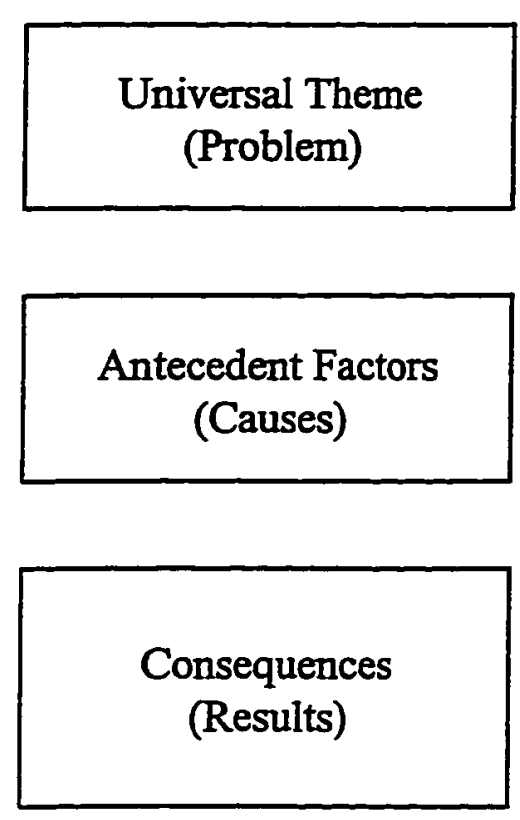

Core Elements (Ways to Respond)
Breakdown in transmission of cultural health beliefs and practices about pregnancy and childbirth among Indian women

1. Assimilation policies:

- Indian boarding school

- Relocation programs

2. Consequences:

- Acculturation/attachment

- Loss of language and identity

- Loss of traditional roles

3. Ways of Responding:

- Culture-affirming responses

- Risk-generating responses

CULTURAL PATHWAY: "Balancing two worlds"

Overarching Theme
- Traditional "Indian"

- Contemporary "Modern"

Figure 1. Categories and relationships in theoretical model. 
All seven women agreed that they had learned to adapt or acquiesce to a changing world. Wolf remembered a shifting and balancing act within her parents' world. The lack of traditional connection for her mother was balanced by adapting to her husband's connection with his tribal culture, extended family, and politics. This gave Wolf and her siblings the opportunity of living in the "best of both worlds" and learning to balance both of them:

My mom didn't talk about [cultural] stuff in the 1950s, at least not openly, and I don't think my grandmother told her very much because they were from such different cultures; my mother was really modern lady in the 1950s and my grandmother was a real traditional lady, so I don't think they exchanged information. I think it's too bad because I think my mom missed out on a lot, and I think, in turn, we did too.

Families of origin for these participants valued the pursuit of higher education for their children in order "to learn to fight the white man's way." For example, both Bear, a professional woman with two children and four grandchildren, and Wolf, a single, new mother, shared common backgrounds. They were both surrounded by Indian leadership-their fathers and grandfathers were tribal councilmen. They agreed that the "trade-off" in their parent's choice 
between education and culture, was not easy, but one that had to be made. They recognized their core traditional tie with tribe and extended family as a way of life. Both were highly educated and accepted their education as a way to accentuate culture, and were seen as invaluable for their families and future. They perceived the choice to use both worlds as the pathway to learning was directly enhanced by their tribal way of life.

Essentially, this group chose to learn, to use, and to share experiences from the "best of both worlds" rather than from one or from the other. Coyote, a tribal health program manager, and Salmon, a homemaker, both expressed a concern that even now "there is a need, at times, to jump back and forth between one world and the other." Coyote had been married for the most years to the same spouse, identified her generation as being "adaptive, [by] keeping [both worlds] separate from each other. I can go into one [world] and then back into the other [world]." She recognized her generation as the missing link, fitting somewhere between the traditional and contemporary lifestyles and having the ability to adapt: "Yes, we're still adaptive, we keep them [world views] separate, keep them from each other."

Wolf spent many years off-reservation attending to higher education, while in her 40s: "I still live on the reservation and go to berry feasts and root feasts. I can give my son both [worlds] - learning with my son, and yet I have other things I can give him from being off-reservation and going to school." 


\section{Contradictory World Views}

The contradiction in the two world views was expressed among these Indian women born in the 1940s and 1950s. The primary themes were identified as the "modern" contemporary paradigm and the "traditional" Indian paradigm. Both themes were expressed in childhood experiences recalled by this group, and in memories of their mothers, the "modern women" of the 1950s. This seems to have created distance and conflict between the "modern" women and their "traditional" grandmothers, as it became obvious that the solution for their mothers was to adapt or acquiesce to a changing world.

Looking back, most women remembered as children being cared for by traditional grandmothers who spoke very little English and parents who only spoke their native language at home and, therefore, did not teach it to them. For example, Eagle a spiritual elder of the tribe, spoke her native language fluently and although she understands the language now, she does not speak it well anymore and chose to teach her grandson only a few words.

\section{Traditional Indian World View}

These women learned mostly from elder family members, and less often from their own mothers. The primary reason was that during that period, traditions and culture were not valued and the focus was on acculturation. One example was Fox who remembered learning about pregnancy and childbirth mostly from her 
elder family members since her mother had left her in her grandmother's care since infancy. Her grandmother was "very strict" and she remembered that her "education in infant care was based on experiences of caring for her nieces when her sisters were out." She realized that the cultural survival of the tribal community is synonymous with that of the individual:

I carry on everything I can. I'm "giving clothes" this week. And its something our younger people don't understand anymore and they aren't taught by some of our elders. I was forced, well not forced, but I was there with my grandma and so now with my sister passed away, they asked me what we do. So I pulled everybody together and told them this is what we do and we do it, and how we do it. Sometimes my family thinks I am an elder, but I am not. It was the way I was taught though.

Respondents remembered learning about preparation for babies beginning in pregnancy and warnings that what you did during pregnancy would directly affect the baby. Pregnancy was not considered to be an illness, a good attitude was essential, as well as refraining from drinking and smoking, and adequate exercise and rest were all mentioned to them by their elders. 
These traditional tribal values characteristic of Native American extended family preparation for pregnancy and childbirth are also characteristic of the Western model of "good" prenatal care. Eagle also remembered learning things from her mother:

Many times I do remember my mother in earlier times say that pregnancy was not an illness; and of things that I couldn't do and couldn't eat and I respected that part, and the diet too, and I listened to her. I also listened to the doctor about vitamins and he told me to take them.

Salmon remembered pregnancy as: “. . scary, and yet at the same time I was glad, my whole attitude about it was important because I knew it would affect my baby."

Bear recalled her grandmother telling her aunts about self-care during pregnancy, and overhearing what she told them. This included good nutrition and exercise. She remembered overhearing her grandmother telling her aunts:

She said that anything that you put on your body will go directly to your baby so that you don't use lotion or underarm deodorant because it will go directly to your baby. What you eat will go directly to your baby, so she 
would emphasize that it was important not to just not sleep in and to exercise, and when I grew up and remembered some of that, and was pregnant with my son and daughter, it was reemphasized to me. I still followed the same things that my mother and grandmother passed down to me. My son was born in 1975 and then my daughter was born eight years later.

Understanding the kinship network as a major factor in the Native American traditional world view is critical. For example, responsibility for caring of children in the 1940-60s was seen as a normal role experienced in Native American families. These households often contained two or three families. Eagle agreed that there were always families sharing a common household with kids around "I didn't know anything different until I went to boarding school, and it was different in boarding school." She teased, "so, we can jog some memories now" (chuckling to herself).

Eagle remembered being "comfortable with pregnancy and looking forward to it." She went to the tribal clinic to verify pregnancy, she remembered there were no obstetricians available, so she went to a nearby town. She based her comfort level on her traditional, cultural, and spiritual training as a child. She learned more from her family, as "a way of life" than she did from contemporary health 
providers: "Because from the time I was little, I took care of children and care for them from that time I was nine years old. I grew up taking care of children, because we had many gatherings at our home, and it was the way I was brought up."

Coyote also remembered caring for children at an early age:

... for me, babies were born at home, and babies were part of life. . when I was younger, we weren't fortunate to have a house, you might have two or three families in one house. Well, someone would be pregnant, there's a baby, you're aby sitting; so babies were not a foreign thing, and babies were born in the home. So it wasn't just being told, I think it [parenting] was being modeled; it was [a way of] life.

\section{Culture and Contradictions}

The rich cultural and spiritual connection with tribal ancestry, history, and extended family was represented in stories about traditional practices such as making and using the cradle/baby board for tribal women, and traditional wisdom such as preparation for childbirth. Ways of sharing cultural beliefs and practices were mentioned mostly by Bear, Eagle, Coyote, and Fox, since they were raised by 
elders or traditional parents. The others, Owl, Salmon, and Wolf may just have had less to say about ways of learning traditional cultural wisdom.

The careful preparation and significance of the rosebush and other materials used in making the cradle board are for the protection of the infant. In stories shared by Bear, she learned to adapt to cultural conflict and stress with health care providers and was modeling "adaptation" for her daughter:

We [in my tribe] don't make the baby board until after the baby is born, so for her baby I didn't start her board until she had the baby. And then I went home and started making the board. I taught my daughter how to put the baby in there, how to put the donut in there, how it shapes the baby's head, and they don't know that the mattress should be made of cotton rather than polyester; it's better. The bow in our [tribe's] belief is the rose bush, and is protection for them; and the rosebush has a lot of protection, because they use it in the birth, and as a cleansing in death.

It was really impressed on me that the nurses really don't like them [infants] in the baby boards, and I felt that was really strange, but I decided that I would take the board in there anyway. It was amazing, when we put the 
baby in the baby board, he just slept, he really slept good. We took him out for his feeding, and they really didn't want to encourage it.

She [the nurse] went on to say that, it came as if we abuse the use of the baby board, and don't allow our children to exercise. Things like that is what she said. And I said to her, "Well, I don't think you know the importance to our people."

Yet, the contradiction in values was experienced as disrespect from contemporary health care providers toward this Indian woman and toward her cultural beliefs and practices. "Adaptation" was a way of life. Wolf had spent years away from the reservation attending law school. She remembered that her cousin "who is older than I am" made a cradle board for her after the birth of her son, and presented it to her and her family in a "blessing" ceremony. Although she was unfamiliar with the significance, she continued to learn about traditions and cultural beliefs and practices:

She came to my house when it was finished and we had a little ceremony and I put him in there, and I had his dad come and she talked about the importance of the board and it was a real learning experience for me, 
because I knew there was a lot of good reasons for having the baby board. It made me miss my grandmother.

Bear remembered a blessing ceremony from her traditional upbringing: "diapering" they call it in English. But when a new baby was born, both families came together and they had a gathering where they Indian traded and blessed things they were going to do for that baby. So it went on from birth to marriage and into death. The families carried this on and that's something they don't do anymore.

An exemplar of provider cultural insensitivity was recalled by Fox involving the use of the baby board. She role-modeled for her niece "adaptation" in a world that can be overwhelming and oppressive towards young Indian mothers with cultural beliefs and practices that are perceived as different from mainstream culture:

I grew up in the old fashioned way; one thing that was told to me was over the last weekend, was to take that baby off that [baby] board "she's suffocating." And I looked at that lady and said "no, she's not." And I said 
"the wind's blowing and if I don't put her on the board, she'll get colic or she'll get sick, and it's a protection so you leave us alone." And she said she was a nurse and said "that baby's going to suffocate in there because it's so hot." It was about 90 degrees out. I told her "there's nothing wrong, the baby's sleeping." After I walked off, she walked up there and took the baby out of the board and laid her on the ground and told the mother, "you keep that baby out of the board, you don't put her there, you're going to kill her." She came and got me and told me "that lady came and took the baby out of the board." And I said "What?" "The one that was a nurse said I was going to kill my baby." I said "no" and so I put her back [in the cradle board].

Cultural insensitivity was recognized as a major barrier on the reservation for Native American pregnant women by group consensus. Insensitive nurses, in particular, were perceived to be most disrespectful about cultural health practices, in this case, the traditional use of the cradle board by young Indian women. Unfortunately, health providers' reactions to cultural practices different from their own results in building more barriers for young Indian women, especially for those who may not have had strong Indian role models to link the two worlds. 
Indian Humor

Indian humor was a strategy used by these women that was sprinkled throughout the interviews, and provided evidence that it builds connectedness among the group relieves stress within the group (Herring, 1994). Laughing and joking was a major way of responding to questions that became emotionally-loaded and complex, as they delved into memories that had often long since been forgotten. For example, in response to the first question about difference between now and then, Salmon responded:

Besides being out of shape? (chuckling). There was nobody to talk to though about when you would menstruate, or when you had your monthly. I finally went home and told my mom and told her I got my period. But the matron told me "If you ever miss your period, then come and let me know." (Laughing) I had no idea what she meant. Okay, I was so naive, (laughing) I didn't know that when you missed your period you were pregnant (laughing).

Another exemplar of Indian humor that seemed to connect these women was their responses to the question "What are some of the ways that you share information about pregnancy and childbirth with young women?" 
Straight out; how you make them (followed by chuckling.)

I told mine, "it really hurts" (laughing). Don't have any until you're thirty, heh, no, I didn't really say that. (More laughter).

Humorous responses evolved as spontaneous one-liners leading to another, and yet another, in short, quick, humorous banter that often resulted in uncontrollable laughter.

\section{Contemporary Modern World View}

Owl married a military man. Her stories of pregnancy and childbirth revolved around "being clueless." Since her husband was stationed away from home, her experiences with health care providers in the past were "scary." She especially missed involvement by her mother and sisters who were at home in Oregon. Owl remembered that she learned most information about pregnancy and childbirth from the physician and from literature available at the time, such as Dr. Spock. She passes on cultural ways, from what she remembers, to young people if they don't know about tribal traditions, but she perceived that some traditional ways are being revitalized within the culture, such as the use of the "baby board and breast feeding." 
I didn't go to the base hospital, I went to a doctor in the city, but I was clueless. If I knew then what I know now, I just didn't have access to information. There wasn't prenatal classes, I just went in and had my baby. My doctor was excellent, but the labor was hard, but again, I was just unfamiliar with all of that, and it was a very scary experience. I remember having nightmares after having my baby, and it was just strange, the whole delivery system, and I just wasn't familiar with it, and I was away from my family, my mother, and my sisters.

Wolf recently delivered her first baby in 1995 . Her mother attended childbirth classes with her. She gained most information about pregnancy and childbirth from prenatal classes, her physicians, reading, and less from her mother. The contrast between generations was apparent:

And my mother was just amazed at how much information there was now; we watched this video on childbirth and she was scared for me. She said, "I don't think you can go through that" and I said, "mom, you went through that; every woman that has children goes through this." She just talked about how she felt then, like the pain, and of being anesthetized during 
delivery. Although she hadn't realized the risks of going under anesthesia, that hadn't been discussed with her.

One thing I was really fortunate, because I was an older pregnant woman, so I went into a higher risk category, so the IHS referred me to an OB and I was able to choose which one I went to, and I wanted a woman who had children, and that made a difference for me. It really did. So I think things are better for kids today. I heard they're better than the 1960s.

Eagle and other women were also well aware of the high incidence of alcohol and drug abuse and domestic violence experienced today by young Indian women and their families:

They [young pregnant women] don't want to get prenatal check ups because of their [substance] use. They're afraid they'll be found out, which they eventually will, but many times they are so much into their habit that they just don't know why. They say they don't use anymore, but it shows up in their newborn. 
Coyote voiced concern about the increase in teen pregnancies and FAS on the reservation, and the need for education in the dangers of alcohol and drug use during pregnancy:

Seems like we have more younger girls becoming pregnant and as Eagle was saying, I was wondering how many generations are there that have Fetal Alcohol Syndrome. And you think back, ladies were drinking when they were pregnant and you see those children and then you look at maybe a couple more generations and the effects of FAS on the babies, and wow, that's one of the differences I see.

Fox had lost a child due to her own drug abuse as a young mother and hoped for a better way to educate young parents about the consequences of substance abuse during pregnancy: "I wish there was a way to show how these babies suffer."

Major differences between the past and present experiences of health care were described by women, including Bear, a new grandmother. These major differences included an emphasis on patient rights, choices in physicians, and opportunities for more information and education: 
As a coach for my daughter I could see a big difference between the time I had children, and when she had hers. In fact, my grandson was just a week old and what really impressed me was they really emphasize the rights they have now, a hospital plan with a list of everything they want.

When we had our babies, we just laid on the bed. They emphasize natural gravity now; they have an opportunity to get up and walk around and where they just put us in bed. My daughter had a female doctor and with IHS In my day, you basically went with what was available. And a lot of times they really didn't tell us what they were doing. Information was really different from when I had my babies, and when my daughter had hers.

Salmon, mother of six, remembered improvements in services today as mainly accessibility to information and services that are available today to young women: "There's so much more available now, whereas before, we had to seek it out. I think the only care we got was the three days we got in the hospital. If we seek it out we got help, it wasn't as openly available as it is today."

\section{Discovery}

These findings support research identifying the rich cultural and spiritual sense of connection with tribal ancestry, history, and extended family associated 
with resilience among traditional Native American families (Cross, 1995). In this way, findings also support research about the importance of the intrinsic worth of the extended family in Native American communities. Evidence also supports research about the prominent place that the family holds in the lives of Native Americans and that the survival of the individual is synonymous with that of the community (Garrett \& Garrett, 1996).

Adaptation to the changing, new culture was facilitated by learning from their parents, and continuing to learn from their grandmothers' wisdom for these women. As young women, they recalled that the more acculturated they became, the more aware they were of the costs in losing cultural sinew. However, these women talked about reestablishing their cultural connections with grandmothers and other traditional family members in order to balance their worlds. Overall, it was seen as important to keep access to traditional cultural wisdom alive through the oral traditions among Indian women, before it was lost forever.

Discussions about children were framed as central to family activities. Care-taking was seen as a normal, routine, activity of family members. The value placed on preparing for a baby in pregnancy was again indicated by these women as a critical feature of "traditional cultural wisdom" learned from mothers and grandmothers that parallels "good Western" prenatal care, as had been identified in other studies (Horn, 1992; Long et al., in review). 
Women discussed traditional practices associated with pregnancy and childbirth. They were most aware of ceremonies including pow wows, namings, giveaways, first kill, and first fish. They were less aware of practical traditions about pregnancy and childbirth. Elders in the former study (Long et al., in review; ROMPP, 1995a) were eager and willing to describe home births and other major cultural events associated with pregnancy and child birth that seem almost to have disappeared from the experiences and memories of this group of women, and from the younger group of women.

Contemporary health care providers and systems have been actively involved to some extent during the participants' pregnancies. Their experiences were described as sometimes "scary" and were compared to improved contemporary experiences with their daughters, as far as technology and greater opportunity for choice. All too often, discussions were about cultural insensitivity, inappropriate services that did not address substance abuse and domestic violence, and less than desirable IHS physician-patient relationships.

The Pathway

In the ROMPP study (1995a) the elder generation and the generation of young women associated forced assimilation with the loss of the traditional pathway for sharing knowledge about prenatal care (Long et al., in review). 
Indian women in this dissertation study were also affected by experiences with Indian boarding schools, and relocation programs. However, they learned to adapt to two contradictory worlds by "balancing both worlds." They learned about pregnancy and childbirth from their elders, less often from their mothers, and more often, from contemporary health providers. They chose to share information with younger family members from the best of both worlds. They also perceived a loss of the traditional pathway and suggested that the pathway be revisited by prevailing models of health care, allowing for more information flow between elders and young Indian women. They utilized a core traditional Indian world view, and they have adapted to the contemporary world view, as well.

Importantly, they felt they could function very well in either world, as long as they kept them separate. Methods this middle generation of Indian women learned and shared concerning cultural health beliefs about pregnancy and childbirth can be now integrated into the diagram of the cultural pathway of Elders and young Indian women identified in the ROMPP Study as the missing link (1995a) in Table 7. 


\section{Table 7}

Pathway of Cultural Transmission by Elders and Young Indian Women About Pregnancy and Childbirth Elder Generation (born before 1935) ${ }^{1}$

- Learned traditional beliefs more from elder women.

- Shared mostly traditional beliefs with younger family women.

- Perceived a loss of traditional roles in transmitting cultural beliefs.

- Would like to be more involved with health care providers and young women.

- Utilized a traditional (Indian) world view.

Middle Generation (born between 1935 and 1965) ${ }^{2}$

- Learned how to adapt health beliefs to two contradictory worlds- -"balance two worlds"-from the best of both worlds; grandmothers, mothers, and contemporary health providers (literature and physicians).

- Shared health beliefs from the best of both worlds with younger family members.

- Perceived a loss in the traditional pathway about pregnancy and childbirth.

- Suggested that traditional pathway be revisited by health care system, allowing for more shared information among elders and younger women.

- Utilized core traditional (relational) world view and adaptation to the contemporary (linear) world view. 


\section{Youngest Generation (born after 1965)}

- Leamed traditional beliefs more from elder women.

- Shared mostly traditional beliefs with younger family women.

- Perceived a loss of traditional roles in transmitting cultural beliefs.

Would like to be more involved with health care providers and young women.

- Utilized a traditional (Indian) world view.

${ }^{1}$ From ROMPP 1995a. ${ }^{2}$ From dissertation study.

Although these separate and individual situations studied in the dissertation clustered into three sets of categories that emerged as a way of dealing with the breakdown in transmission of cultural health beliefs and practices among Indian women. It is recognized that there may be other variables affecting responses of the individuals. It is possible that other meaningful events were either not recalled or forgotten. The dissertation study relied upon the lived experiences recalled by the participants.

\section{Grounding Hypotheses}

As previously discussed in the process of collapsing and comparison for the middle group of women, the overarching theme was "balancing both worlds." The world views included the core "traditional" Indian world view and a contemporary 
"modern" world view, oftentimes contradictory. Collapsing domains of constructs and establishing the relationship between them were complex activities necessary in grounding hypotheses and theory.

As has been shown, Indian assimilation policy has played a major role in breaking down the process of intergenerational transmission of cultural health beliefs and practices. By removing successive generations of native children from their families and communities so that they could be educated, the loss of language effectively placed children beyond the reach of storytellers-those that passed down wisdom and the history of the people. Relocation programs also played a major part in disrupting cultural transmission. Ways of responding were identified as either risk-generating or as protective, leading to the following hypotheses.

\section{Discussion of Hypothesis 1}

Indian assimilation policy has been shown to have traumatic effects on Indian women born within a specific time and context, contributing to the breakdown of intergenerational cultural transmission about pregnancy and childbirth (cultural wisdom). This has resulted in many levels of acculturation, loss of language, loss of self-identity, and loss of traditional roles. As a result, in some native communities, the oral tradition is on the brink of extinction. Elders are passing away and there are fewer and fewer young people who are able to speak their native language and, therefore, carry on the oral tradition. Some elders 
still insist on the traditional way of transmitting traditional cultural wisdom that has been protected within families and kinship systems. Others emphasize the need to preserve and revive this tradition before it is too late. A major consequence is the loss of the intergenerational traditional pathway among women.

Traditional "cultural wisdom" parallels "good Western" prenatal health care that prepares for a baby beginning in pregnancy by emphasizing a healthy diet, adequate exercise, abstinence from substances, and maintaining a positive attitude.

Hypothesis 1: The traditional pathway to cultural wisdom about pregnancy and childbirth among Indian women is transmitted by Elder women among kinship systems within the community. The breakdown in the transmission of cultural wisdom among Indian women is associated with the acculturation process.

\section{Discussion of Hypothesis 2}

The cultural pathway used by this middle group of Indian women was adaptation to the contemporary Western perspective by "balancing both worlds". Although they experienced a trade-off in what they gained and lost in cultural wisdom, they also perceived a critical need to re-establish access to the traditional pathway for young Indian women within the existing Western health model. 
Indian women are obviously affected by their social and cultural system, their spiritual definition, their opportunities, and their stability. Indian women in this study made adjustments to cultural paradigms and choices, basing their lives on the values and options afforded them in their social, political, and cultural context. This is reflected in their prenatal health care systems.

In this dissertation study, there is further evidence that prenatal health choices are associated with effects of social, cultural, and spiritual systems identified in the stories about the social reality of pregnancy and childbirth for this middle group of Indian women and their past and present experiences with the Western model of prenatal health care. Exemplars include the meanings and values held by this middle group of Indian women towards extended family, children, traditional roles of grandmothers, and humor; and how these factors contribute to their perceptions about using Western models of prenatal health care.

In the political context, federal assimilation policies have been experienced as impacting the breakdown in transmission of cultural health beliefs and practices for this middle group of Indian women. The consequences has affected the cultural pathway among Indian women.

Social, political, and cultural values and options that have been afforded this middle group of women are couched in stories about the hardship and loss of culture to their mothers and, although, they had learned to balance two worlds 
themselves, they also realized that the traditional cultural pathway about pregnancy and childbirth between grandmothers and granddaughters has been disrupted.

Hypothesis 2: The adaptation/acculturation by Indian women to the Indian traditional perspective and also to the modern, contemporary perspective is associated with opportunities for accessing traditional cultural wisdom expressed in their prenatal health care choices.

\section{Discussion of Hypothesis 3}

Ways that this middle group of women dealt with the breakdown in cultural transmission provides further intergenerational linkages that had been missing from the ROMPP findings (1995a). The literature on resiliency in the Native American community tells us that what makes the difference in one who survives all predictors of failure may be a traditional grandmother who instills in that child a belief in her ultimate power to restore balance in her own life and destiny, who trains her to believe that success and failure are directly attributable to the individual's own choices within the group, rather than in comparison with mainstream society (Cross, 1995).

In describing responses to the Ethnic, Cultural, and Religious (ECR) Scale, the women in the middle group reported positive self-identification with their 
Indian culture, their families and community support systems, their language use, and their spiritual identity. These cultural factors are associated with resiliency (Cross, 1995). This relational model promotes balance and harmony and therefore, resiliency.

This evidence supports research that identifies the connection between tribal ancestry, history, and extended family associated with Native American family resiliency (Cross, 1995). Women in this middle group also identified the prominent place that the family holds in the Indian community.

Hypothesis 3: There is an association between culture, ethnicity, and resiliency among Native American women which is expressed in their prenatal health choices.

\section{Discussion of Hypothesis 4}

Exemplars included accounts of assimilation policy and of their childhood when being Indian was not valued. Self-identity was fragmented. Yet, today, positive cultural identification is present in their stories and described in the information gained from the ECR scale. 
Stories also recalled the devastation to the reservation community when alcohol became legalized in the 1950s. Contemporary concerns were for substance abuse associated with family violence during pregnancy.

May's (1982) social integration continuum suggests four types of adaptation which contemporary Indian individuals make that reflect their level of acculturation and, therefore, susceptibility to risk-generating responses. Based on the findings from the ROMPP study (1995a) and this dissertation study, May's levels of acculturation have been combined with Cross' resiliency model to create the explanatory theoretical model which was the final product of the dissertation. (See Figure 2.)

Hypothesis 4: The adaptation/acculturation by Indian women to the Indian traditional perspective and also to the modern, contemporary perspective is associated with risk-generated responses by Indian women which influence their prenatal health care choices. 


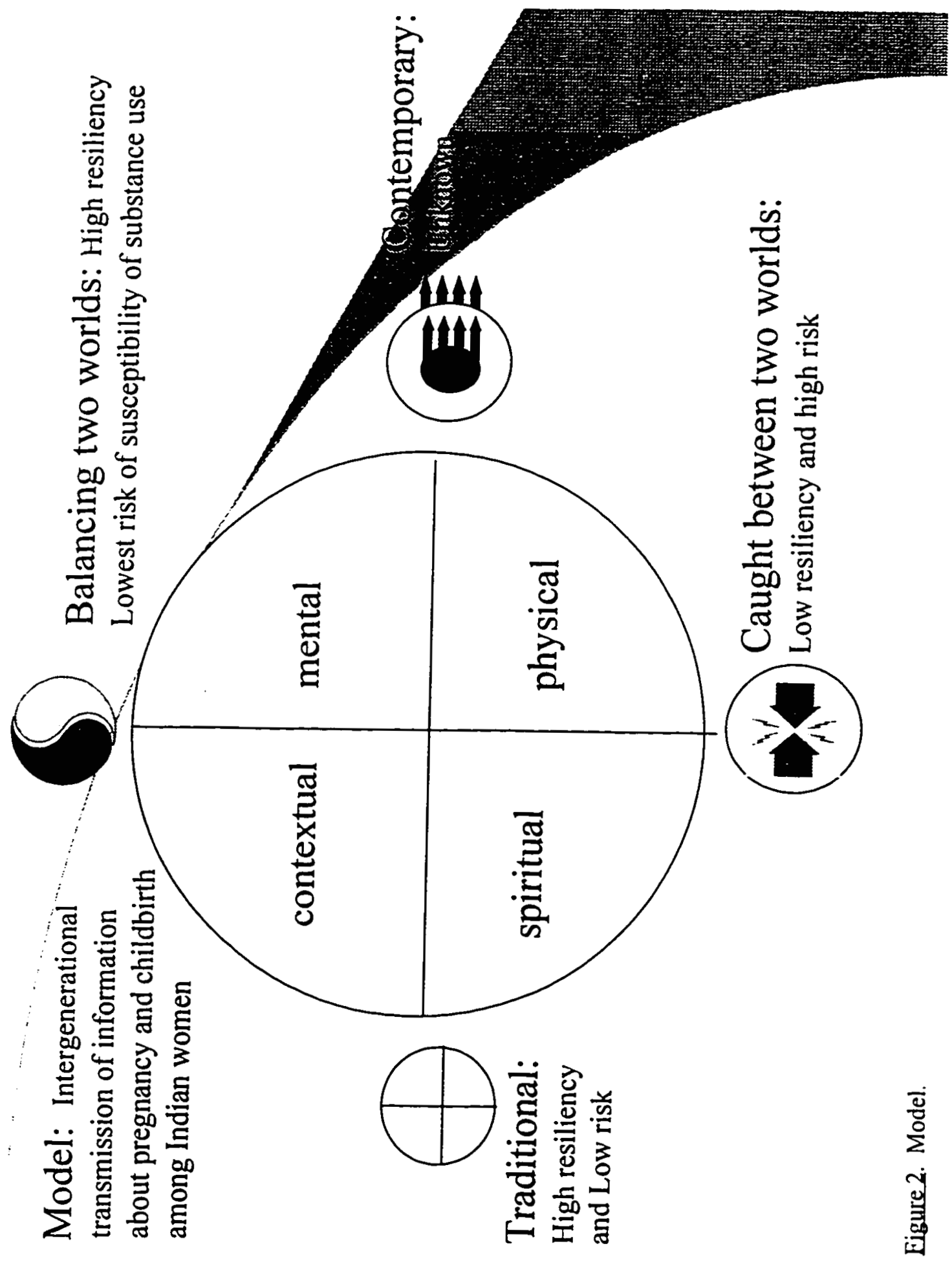




\section{CHAPTER FIVE \\ THE MODEL, DISCUSSION AND IMPLICATIONS}

Theoretical Model

As discussed in the last chapter, this study has addressed three important conditions which affect the breakdown in transmission of cultural health beliefs about pregnancy and childbirth among Indian women: (a) assimilation policies, (b) consequences, and (c) ways of responding. These factors interact and are consequential to Indian women's accessibility to different pathways leading to information about pregnancy and childbirth.

Evidence from this study supports research about the profound effects of federal assimilation policy such as boarding schools and relocation programs that sent young Indian people and to their families to cities for education and training, disrupting Native American family systems (Atkinson et al., 1993; D’Andrea, 1994; Long et al., in review; Williams \& Ellison, 1996).

This study provides further evidence for research about consequences of forced acculturation resulting in loss of Native language and customs forbidden in boarding schools in order to weaken oral tradition and connections with tribal culture (DeLoria, 1969). During their parents' era, being Indian was not valued and self-identity during their own childhood was fragmented and diluted. This study also provides evidence that grandmothers are recognized as natural helpers 
and cultural transmitters about pregnancy and childbirth (Bushnell, 1991; Horn. 1982). Examples are given of varying levels of acculturation exhibited by Indian people due to federal assimilation policies (Garrett \& Garrett, 1994; Locust, 1988; May, 1982; Williams \& Ellison, 1996).

Culture-enhancing responses are also discussed in this dissertation study as well. As children, this group's experiences with conflicts between Indian and Euro-American culture were obvious as they were sent off to boarding school to learn "modern" ways. They learned how to balance their lives by using their own culture as a source of strength and renewal. Cultural practices and language were often forbidden during this era, but Indian humor and group loyalty among peers created systems of cultural support. In a study of successful adaptation to a boarding school in the 1920-30s, peer group loyalty in kinship terms was stressed: "We were brothers and sisters" (Lomawaima, 1994, p. xiv).

Later, as young women, in relocation programs, moving away from home and culture, and away from what they knew, again, they built cultural support systems with other Indian people by attending cultural/social activities. These coping strategies that women used were the ways they maintained a source of cultural strength, resiliency, and connection in their lives.

Loss of identity and culture were sometimes responded to with riskgenerating behavior. Evidence of the influence of culture and acculturation on 
intergenerational drinking patterns and habits for Native Americans associated with family violence is provided in this study (Choney et al., 1995). A major contemporary concern expressed by these women was the use of alcohol during pregnancy and family violence. Possible consequences of substance use for the unborn baby such as fetal alcohol syndrome was a concern expressed by these women.

Cultural pathways used by women toward gaining cultural wisdom differed greatly depending on their levels of attachment to a culture (May, 1982). The pathways are illustrated in Figure 2, a medicine wheel illustrating the theoretical model generated by this research. For example, the pathway used by the middle group of Indian women (in the dissertation study) was opposite from the young women in the ROMPP Study (1995a). The middle group used wisdom from both worlds (balancing both world views) and they shared mostly within their own families. In opposition, young women (ROMPP, 1995a) learned little from elders or Western health care providers and had neither cultural perspective (caught between two worlds).

Traditional Indian women (ROMPP, 1995a) had learned (as young women) from traditional elders (traditional world view) and shared within their family systems (Long et al., in review). The assumption is that opposite the traditional world view is the contemporary world view. Indian women who learned mostly 
from Western health care services are considered adapted to the contemporary world view. This pathway would be the focus for future research.

Since the Western prenatal health model does not yet recognize or make allowances for differences in culture (Dubray, 1985; Luckey, 1994; Mokuau \& Fong, 1994; Parker et al., 1992; Sue \& Sue, 1990), acculturation (Choney et al., 1995; Locust, 1988; May, 1982; Williams \& Ellison, 1996) or aspects of resiliency (Cross, 1995; Dubray, 1985; Lum, 1993) common to Indian women and their families (Long \& Nelson, in press), the implications are immense.

\section{Summary: Pathways to Cultural Wisdom}

The process of the breakdown in cultural transmission about pregnancy and childbirth among Indian women and the associated pathways are best illustrated by using a symbol common to tribal systems.

The Medicine Wheel

The medicine wheel symbolizes the cyclical nature of the relational Indian world view that seeks balance and harmony. The four lines represent the pathways and symbolize the four directions. Within the circle of the medicine wheel, the mental, physical, spiritual, and contextual parts of the human being are represented (Cross, 1995; Garrett \& Garrett, 1994; Garrett, \& Meyers, 1996). In the relational world view, these aspects exist in an intricate system of interdependence and a dynamic state of harmony and balance. Traditional Native American culture views 
health as seeking a balance of these aspects of life (Garrett \& Garrett, 1994). In contrast, these aspects are addressed in the Western world view as separate and as linear rather than relational.

In the illustration of intergenerational transmission of cultural health beliefs about pregnancy and childbirth, the four points of social/cultural attachment (or integration) are identified at opposite ends of the spokes in the medicine wheel as contrasting and contradictory. As a part of the process, the model theorizes four interrelated pathways to information about pregnancy and childbirth based on the relationship with context and time.

Utilizing a theoretical framework with a focus on strengths and resilience, and on social/cultural norms and values within Native American groups and their attachment/integration to a culture, it is hoped that this model will advance knowledge and encourage further exploration about how culture, acculturation, and resiliency may influence prenatal health choices.

The model described is a logical extension of symbolic interactionism, acculturation theory, and resiliency models. Although the Native American "Intergenerational Pathway to Cultural Health Beliefs Among Indian Women" model is inconsistent with a list of linear characteristics common to acculturation schema, it is consistent with the relational world view characteristic of Native American culture. 
The theoretical framework is grounded in existing theory about symbolic interaction that people construct meanings for phenomena based on their interpretations in cultural beliefs and stories; on resiliency factors that provide protection in circumstances of stress and crisis; and on the relational perspective that allows for factors such as diverse cultural beliefs and values (tribal and family significance, respect for elders, traditional roles of women, and so on) to interact.

\section{Strengths and Limitations}

There are growing numbers of women taking the lead on women's health issues in research and policy who are themselves members of minority groups (Olson, 1994). Clearly, culturally competent research techniques were illustrated in the study. For example, a Native American researcher conducted the research with Native American communities; tribal community members were involved as intermediaries to actively recruit participants; and the grounded theory approach used was culturally appropriate (Weaver, in press). These research techniques promote culturally competent social work (Browne, Broderick, \& Fong, 1993; Sue, Arredondo, \& McDavis, 1992; Weaver \& Wodarski, in press) that includes respect for the participant's cultural context, history, and world view. These research techniques were also evidenced in the emergent research design and methodology used in this study that will focus benefits back to the community. 
My understanding from past studies with elders and young Indian women (ROMPP, 1995a) increased my awareness of the socioeconomic, political, and cultural spheres associated with the breakdown in cultural transmission and prenatal health choices. My appreciation and respect for Indian women faced with adversity were enhanced by my learning about their experiences with coping strategies used to maintain culture and traditions, and in their courage, strength, and resiliency.

Findings were limited by sample size and by context. Therefore, transferability to other populations cannot be made from specific experiences of these participants. However, the common experiences shared among these participants suggests that the process of intergenerational cultural transmission among Native American women residing on-reservation may be transferable.

As the instrument of measurement in this qualitative study, the researcher's emotions were impacted by the thick descriptions shared among participants that gave way to feelings of sadness, anger, frustration, and hope associated with conducting this type of research. The process of interviewing, reflection, and constant comparative methodology demanded time to reflect on my own beliefs, values, and biases and how these may impact the study. Based on an awareness that social workers may feel more positively and act more favorably toward clients that are perceived to be similar to themselves (Weaver, in press); this phenomenon 
(with researchers) was taken into consideration during the constant comparison process.

\section{Implications}

The findings from this study will be applicable to social policy and practice only if they concern a population from a similar context and time. For example, outcome themes from this research could be considered for other Native American communities that resemble a reservation in Oregon. Implications from this study are focused towards further qualitative and quantitative research that will enhance the knowledge about Indian women, culture, acculturation, and resiliency associated with prenatal health choices.

\section{Social Work Practice}

This model is based on identification of strengths rather than on the deficit approach. The strength of the relational model, again, is that it gives us a way to understand how Indian women, acculturation, and resiliency interact. Although there is an interest in cultural relevancy in practice with Indian communities there is a lack of knowledge about cultural factors.

In this study, resiliency is recognized as ways that Indian women maintain balance in their lives. This study supports the approach that describes Native American women's dependence on oral history and stories as major vehicles to construct meanings. 
Women were able to discuss their connection with the traditional way of life that can be identified as a resiliency factor used in times of stress during their lives. The intrinsic worth and prominent place that the extended family holds in the lives of Indian women were also discussed. Survival of the individual is seen as synonymous with that of the community. Implications to practice begin with identifying strengths in the family that are parallel to identification with the community at large.

It was seen as important by this generation of women to keep access to traditional culture alive through the oral traditions among grandmothers and granddaughters, before it was lost. Implications for social work practice are inclusion of Indian families in planning and in providing prenatal services. Identification and inclusion of natural helpers in the community are critical in working with Indian women and their families.

Participants in the study recommended that Native Americans be recruited into the health care fields by extension into other helping professions. Recognizing the importance of Native American culture in health, health care maintenance, and health care utilization, traditional pathways should be incorporated into Western health and social service systems. For example, prenatal health care should be inclusive of cultural beliefs and traditions provided by natural helpers such as Elders. 
The Cross Ethnic Culture Religion/Spirituality (Cross, 1995) instrument would seem to be an excellent source of information for assisting health care providers and social workers to look at strengths, resiliency, and positive aspects existing in the tribal community. It would also develop a greater awareness and appreciation of cultural factors that contribute to resiliency among Native American women.

Considered together, the sample size was too small to be viewed as a way of measuring resiliency factors self-identified by these women. However, further social work practice can be focused on this type of measurement that quantifies sources of Native American strengths and resiliency rather than problems or risk factors.

\section{Policy}

As the body of knowledge related to the understanding of pregnancy and childbirth through aspects of intergenerational transmission of cultural belief and practices expands for Native Americans, attention will increasingly be placed on the quality of the prenatal health care experience and complementarity between existing, contemporary Western health care and culturally-sensitive health care structures.

Because of the critical disparity in the health status of minorities, their health and well being is quickly becoming a focus for health planning, policy, and 
program development. It is hoped that this exploratory study will lead to expansion of the research literature about the influence of the intergenerational transmission of cultural health beliefs and practices about pregnancy and childbirth among Indian women to further research that will inform health planning, policy, and program development for Native American women.

For example, although a small group, experiences of Indian women in this study with Indian Health Services physicians were couched in ethical and moral concerns about the relationship between Indian communities and physicians and their "federal payback" status concomitant with their education. Recommendations were that policy makers become aware of this reality on Indian reservations: that the driving force behind IHS staff physicians brief and sporadic time spent on Indian reservations is primarily to pay the government back for their education. Therefore, a shift in focus is needed, driven by a commitment to benefit Indian communities, rather than doctors.

\section{Social Work Research/Knowledge Building}

The controlled and reductive procedures of quantitative research have tended to ignore too much of the context, therefore, missing significant factors that constructivist observation and description might identify. Hartman (1994) suggests that "nothing is more crucial in shaping and defining the social work profession and its practice than that profession's definition of 'truth' and the selection of 
preferred strategies of knowledge building" (p. 459). The constructivist approach that uses grounded theory methodology for defining truth and building knowledge from the experiences of Native American women and the meanings derived about cultural beliefs assures that the social work profession and its practice will be informed and transformed about the resiliency aspects (Cross, 1995) and social integration aspects (May, 1982) in Indian communities.

The study, therefore, informs research and provides a foundation for further qualitative and quantitative study with Native American communities concerning social work interventions that will be culturally-relevant and sensitive to Native American women and that will complement existing systems.

It is believed that this is one of the first studies that examines the linkages between federal policy and its effects locally on prenatal health care perceptions and behaviors of Indian women. Grounded theory contributes to hypotheses that will guide further social work research about Indian women. In this way, this study sought to uncover processes and elicit meanings in interactions in a limited context and time and to develop a model. It is hoped that further research will help to identify, develop, and test interventions to increase participation by Native American women in prenatal health care in substance abuse, and domestic violence programs to reduce infant mortality rates. 
This type of research can build a social work knowledge base that offers insight into relationships across ethnic, class, and gender lines. Such work will only increase our understanding of people and cultures and help us to attend to the lived experience of those who are oftentimes powerless. The trusting, caring, human relationship basic to social work is similar to the reciprocal process in the constructivist approach to research. From the data and findings in this study, quantitative research will serve to complement and verify the hypotheses and central themes and following considerations that are the outcomes of this study.

\section{Summary}

Building bridges to close cultural gaps between grandmothers and granddaughters can be accomplished by building partnerships between Western health care systems and natural helpers in Indian communities. When Indian women and their families collaborate with social work professionals in planning and implementing services. they produce more successful outcomes. These outcomes can be measured by increased utilization of prenatal health care services by young Indian women.

A new approach is needed to focus on cultural strengths and resiliency within Indian family systems that is based on a relational model (Cross, 1995). The intergenerational model, based on this complex relational approach calls on existing cultural support systems and natural helpers to empower young Indian 
women to make healthy choices about prenatal care and substance use.

Susceptibility to problem behavior (May, 1982) associated with acculturation

levels were also identified in this study as a frame of reference for further study

about prenatal health care services, Indian women, and assimilation policy. 
References

Adams, B. L. (1995). Health issues for women of color: A cultural diversity perspective (pp. 27-41). Thousand Oaks, CA: Sage.

Agbayani-Siewert, P. (1994). Filipino American culture and family: Guidelines for practitioners. Families in Society: The Journal of Contemporary Human Services, 429-38.

American Nurses Association (ANA). (1987). Access to prenatal care: Key to preventing low birth weight. Kansas City, MO.

Amed, F. (1990). Unmarried mothers as a high-risk group for adverse pregnancy outcomes. Journal of Community Health 15, 35-44.

Atkinson, D. R., Morten, G., \& Sue, D. W (1993). Counseling American minorities: A cross-cultural perspective (4th ed.). Madison, WI: Brown \& Benchmark Publishers.

Attneave, C. (1969). Therapy in tribal settings and urban network intervention. Family Process, 9, 192-210.

Beane, S., Hammerschlag, C.A., \& Lewis, J. (1980). Federal Indian policy: Old wine in new bottles. White Cloud Joumal, 2(1), 14-17. 
Beckham, S.D. (1991). Federal-Indian relations. In C.M. Baun and R. Lewis (Eds.), The first Oregonians: An illustrated collection of essays on traditional lifeways, Federal-Indian relations, and the state's native people today (pp. 39-54). Portland, OR: The Oregon Council for the Humanities.

Begun, A. L. (1993). Human behavior and the social environment: The vulnerability, risk, and resilience model. Journal of Social Work Education, 29(1), 26-35.

Browne, C., Broderick, A., \& Fong, R. (1993). Lessons from the field: Social work practice with multicultural elders. Educational Gerontology 19(6), $511-52$

Bryde, J. F. (1970). The Indian student: A study of scholastic failure and personality conflict. Vermillion SD: Dakota Press.

Bushnell, J. (1991). Northwest Coast American Indians' beliefs about childbirth. Issues in Health Care of Women, 3, 249-261.

Choney, S., Berryhill-Paapke, E., \& Robbins, R. (1995). In J. G. Ponterotto, J. M. Casas, L. A. Suzuki, \& C. M. Alexander (Eds.), Handbook of multicultural counseling. (pp.73-92). Thousand Oaks: Sage.

Congress, E., \& Lyons, B. (1992). Cultural differences in health beliefs: implications for social work practice in health care settings. Social Work in Health Care, 17(3), 81-96. 
Cross, T. (1995). Understanding family resiliency from a relational world view. In H. I. McCubbin, E. A. Thompson, A. I. Thompson, \& J. E. Fromer (Eds.), Resiliency in ethnic minority families. Vol I: Native and immigrant American families. Madison, WI: University of Wisconsin System.

Cross, T. (1986). Drawing on cultural tradition in Indian child welfare practice. Social Casework, 67, 283-289.

Curry, M.A. (in press). Issues in prenatal care and community-based programs to reduce infant mortality.

D'Andrea, M. (1994). The concerns of Native American youth. Journal of Multicultural Counseling and Development, 22, 173-181.

D'Avanzo, C. (1992). Bridging the cultural gap with Southeast Asians. The American Journal Maternal Child Nursing, 17, 204-208.

DeLoria, Jr., V. (1969). Custer died for your sins. An Indian manifesto. London: The Macmillan Company.

Dubray, W. H. (1985). American Indian values: Critical factor in casework. Social Casework, 66, 30-37.

Dufrene, P.M., \& Coleman, V.D. (1994). Art and healing for Native American Indians. Journal of Multicultural Counseling and Development 22, 145152. 
Duimstra, C., Johnson, D., Kutsch, C., Wang, B., \& Zentner, M. (1993). A fetal alcohol syndrome surveillance pilot project in American Indian communities in the northern plains. Public Health Reports, 108(2), 225-229.

Fleming, C. (1992). American Indians and Alaska Natives: Changing societies past and present. In U.S. Department of Health and Human Services, Cultural competence for evaluators. (LOC Publication No 92-60067). Rockville, MD: US Department of Health \& Human Services.

Garrett, J. T., \& Garrett, M. T., (1994). The path of good medicine: Understanding and counseling Native Americans. Joumal of Multicultural Counseling and Development, 22, 134-144.

Garrett, J. T., \& Meyers, J. E. (1996). The rule of opposites: A paradigm for counseling Native Americans. Joumal of Multicultural Counseling and Development, 24, 89-104.

Geertz, C. (1994). The interpretation of cultures: Selected essays. In N. K. Denzin \& Y. S. Lincoln (Eds.), Handbook of Qualitative Research, (pp. 122-123). Thousand Oaks: Sage.

Glaser, B. G. (1978). Theoretical sensitivity: Further advances in the methodology of grounded theory. San Francisco: Sociology Press.

Glaser, B. G., \& Strauss, A. L. (1967). The discovery of grounded theory: Strategies for qualitative research. Chicago: Aldine. 
Guba, E. \& Lincoln, Y. S. (1994). Competing paradigms in qualitative research. In N. K. Denzin \& Y. S. Lincoln (Eds.) Handbook of qualitative research. (pp. 105-117). Thousand Oaks: Sage.

Guba, E., \& Lincoln, Y. S. (1989). Fourth generation evaluation. Newbury Park: Sage.

Hartman, A. (1994). Setting the theme: Many ways of knowing. In E. Sherman \& W. J. Reid, (Eds), Qualitative research in social work. (pp. 459-463). New York: Columbia University Press.

Hatton, D. C. (1994). Health perceptions among older urban American Indians. Western Journal of Nursing Research, 16(4), 392-403.

Hawley, D. R. \& DeHaan, L. (1995). Towards a definition of family resiliency: Integrating life-span and family perspectives. Paper presented at the Theory Construction and Research Methodology Workshop, Portland, OR.

Henrich, R. K., Corbine, J. L., \& Thomas, K. R. (1990). Counseling Native Americans. Joumal of Counseling \& Development, 65, 128-133.

Herring, R. D. (1994). The clown or contrary figure as a counseling intervention strategy with Native American clients. Journal of Multicultural Counseling. 22, 153-164.

Herring, R. D. (1990). Understanding Native American values: Process and content concerns for counselors. Counseling and Values, 34, 134-137. 
Horn, B. (1982). Northwest coast Indians: The Muckleshoot. In M. A. Kay, Anthropology of human birth (pp.361-376). Philadelphia: F.A. Davis Company.

Institute of Medicine. (1988). Prenatal care: Reaching mothers, reaching infants. Washington DC: National Academy Press.

Khazoyan, A. \& Anderson, D. (1994). Latinas' expectations for their partners during childbirth. The American Journal Maternal Child Nursing, 19, 226-229.

LaFromboise, T., (1988). American Indian mental health policy. American Psychologist, 43, 388-397.

LaFromboise, T., Trimble, J., \& Mohatt, G. (1991). Counseling intervention and American Indian tradition: An integrative approach. The Counseling Psychologist, 18, 625-654.

Lia-Hoagberg, B., Rode, P., Skovholt, C., Oberg, C., Berg, C., Mullett, S., \& Choi, T. (1990). Barriers and motivator to prenatal care among low-income women. Social Science Medicine, 30(4), 487-95.

Lincoln, Y. S., \& Guba, E. G. (1985). Naturalistic inquiry. Newbury Park: Sage.

Locust, C. (1988). Wounding the spirit: Discrimination and traditional American Indian belief systems. Harvard Educational Review, 58, 315-330. 
Locust, C. (1985). American Indian beliefs concerning health and unwellness. Native American Research and Training Center Monograph, pp. 1-25.

Lomawaima, K. T. (1994). The story of Chilocco Indian school: They called it prairie light. University if Nebraska: Lincoln.

Long, C. (1995). Rural Oregon minority prenatal project (ROMPP) study report. Unpublished manuscript, Oregon Health Sciences University at Portland. Long, C., Curry, M.A., \& Burton, D. (In review). Living in two worlds: Native American women and prenatal care. Health Care for Women International.

Long, C. \& Nelson, K. (in press). Honoring diversity: The reliability, validity and utility of a scale to measure Native American resiliency. Journal of Human Behavior in the Social Environment.

Luckey, I. (1994). African American elders: The support network of generational kin. Families in Society: The Journal of Contemporary Human Services, 82-89.

Lum, D. (1993). Cultural values and minority people of color. Journal of Sociology \& Social Welfare, 59-74.

Marshall, C., \& Rossman, G. (1995). Designing qualitative research. Thousand Oaks: Sage.

May, P. A. (1982). Substance abuse and American Indians: Prevalence and susceptibility. The International Journal of the Addictions, 17(7), 1185-1209. 
McCubbin, H. I., McCubbin, M. A., Thompson A. I., \& Thompson, E. A. (1993). Resiliency in ethnic families: A conceptual model for predicting family adjustment and adaptation. In H. I. McCubbin, E. A. Thompson, A. I. Thompson, and J. E. Fromer (Eds.), Resiliency in ethnic minority families, Native and immigrant America families. Vol I. (pp. 3-48), University of Wisconsin System: Madison.

Meadows, J. (1991). Multicultural communication. Physical and Occupational Therapy in Pediatrics, 11(4), 31-42.

Medicine, B. (1987). The role of American Indian women in cultural continuity and transition: In J. Penfield (ed.), Women and Language in Transition (pp. 159-166). New York: State University of New York Press.

Miles, M. B. \& Huberman, A. M. (1994). Qualitative data analysis (2nd Ed.). Thousand Oaks: Sage.

Miller, M. \& Crabtree, S. (1994). Clinical research. In N. K. Denzin \& Y. S. Lincoln (Eds.), Handbook of qualitative research (pp. 340-352). Thousand Oaks, CA: Sage.

Mokuau, N. (1990). The impoverishment of Native Hawaiians and the social work challenge. Health and Social Work 15(3), 235-242.

Mokuau, N. \& Fong. (1994). Assessing the responsiveness of health services to ethnic minorities of color. Social Work in Health Care 20(2), 23-34. 
Mondragon, D. (1993). No more "let them eat admonitions": The Clinton administration's emerging approach to minority health. Journal of Health Care for the Poor and Underserved, 4(2), 77-82.

Morgan, D. (1993). Successful focus groups. Qualitative research methods series 16. Newbury Park: Sage.

Morgan, D. (1988). Focus groups as qualitative research. Qualitative research methods, Series 16. Newbury Park: Sage.

Morse, J. M. (1994). "Emerging from the data": The cognitive process of analysis in qualitative inquiry. In J. M. Morse (Ed.), Critical issues in qualitative research methods, (pp. 23-43). Thousand Oaks: Sage.

Olson, M. M. (1994). Introduction: Reclaiming the "other"-women, health care and social work. Social Work in Health Care 19, 1-16.

Oregon Benchmarks. 2000. (1990). Salem: State of Oregon.

Oregon Health Division (OHD). (1996). Oregon vital statistics annual report. Vol. I-II. Portland, OR: Author.

Oregon Health Division (OHD). (1994). Oregon vital statistics annual report. Vol I-II, Portland, OR. Author.

Parker, M., Quinn, J., Viehl, M., McKinley, A., Polich, C., Detzner, D., Hartwell, S., \& Korn, K. (1992). Case management in rural areas. Journal of Nursing Administration, 22(2), 54-59. 
Peregoy, J. J. (1993). Transcultural counseling with American Indians and Alaska Native: Contemporary issues for consideration. In J. McFadden (Ed.), Transcultural counseling: Bi-lateral and international perspectives (pp. 163-191). Alexandria, VA: American Counseling Association.

Red Horse, J. G. (1980). American Indian elders: Unifiers of Indian families. Social Casework, 61(8) 490-493.

Rhoades, E. R., Mason, R. D., Eddy, P., Smith, E. M., \& Burn, T. R., (1988). The Indian Health Service approach to alcoholism among American Indians and Alaskan Natives. Public Health Reports, 103, 621-627.

Richardson, H. (1988). The health plight of rural women. Women \& Health 12, 42-54.

Robinson, V. M. (1978). Humor in nursing. In C. Carlson \& B. Blackwell (Eds.), Behavioral concepts and nursing intervention (2nd ed., pp. 191-210). Philadelphia, PA: Lippincott.

Rural Oregon Minority Prenatal Project (ROMPP) Qualitative Report. (1995a). Oregon Health Sciences University: Portland.

Rural Oregon Minority Prenatal Project (ROMPP) Pilot Report. (1995b).

Portland: Oregon Health Sciences University.

Rural Oregon Minority Prenatal Project (ROMPP). (1990). Portland: Oregon Health Sciences University. 
Russell, K., \& Jewell, J. (1992). Cultural impact of health-care access: Challenges for improving the health of African Americans. Journal of Community Health Nursing, 9(3), 161-9.

Saleebey, D. (1994). Culture, theory, and narrative: The intersection of meanings in practice. Social Work, 39(4), 351-359.

Sanders, D. (1987). Cultural conflicts: An important factor in the academic failures of American Indian students. Journal of Multicultural Counseling and Development, 15, 81-90.

Schupholme, A., Robertson, E., \& Kamons, S. (1991). Barriers to prenatal care in a multi-ethnic, urban sample. Journal of Nurse-Midwifery, 36, 111-116.

Seidel, (1995). Ethnograph 4.0 (Computer Program). Littletown, CO: Qualis Research Associates.

Sherman, E., \& Reid, W. J., (1994). Qualitative research in social work. New York: Columbia University Press.

Steissguth, A., LaDue, R. \& Randels, S. (1988). A manual on adolescents and adults with fetal alcohol syndrome with special reference to American Indians. Seattle: University of Washington, Department of Psychiatry and Behavioral Sciences.

Stowell, C. (1987). Reservation. A portrait of the Warm Springs Indian reservation. Portland: Oregon Historical Society. 
Strauss, A., \& Corbin, J. (1990). Basics of qualitative research. Grounded theory procedures and techniques. Newbury Park: Sage.

Sue, D. W., \& Sue, D. (1990). Counseling the culturally different: Theory and practice (2nd ed., p. 23). New York: Wiley.

Sue, D. W., Arredondo, P., \& McDavis, R. J. (1992). Multicultural counseling competencies and standards: A call to the profession. $\underline{\text { Journal of }}$ Counseling and Development, 70(4), 477-486.

Taylor, S. J. \& Bogdan, R. (1984). Introduction to qualitative research: The search for meanings (2nd ed.). New York: John Wiley.

Thomason, T. (1991). Counseling Native Americans: An introduction for non-Native American counselors. Journal of Counseling and Development. 69, $321-327$.

Tom-Orme, L. (1995). Native American women's health concerns. Toward restoration of harmony. In D. L. Adams (Ed.), Health Issues for women of color: A cultural diversity perspective (pp. 27-41). Thousand Oaks, CA: Sage.

Tom-Orme, L. (1993). Chronic disease and the social matrix: A Native American diabetes intervention. Recent Advances in Nursing, 22, 89-109.

Tribal Children's Protective Agency (TCPA). (1989). Warm Springs Tribal Protective Agency Report. Warm Springs, OR: Author. 
Uba, L. (1992). Cultural barriers to health care for Southeast Asian refugees. Public Health Reports. 107(5), 544-548.

U.S. Department of Health and Human Services (DHHS), Public Health Services. (1996). Comprehensive health programs for American Indian and Alaskan Natives. Washington, DC: Indian Health Services.

U.S. Department of Health and Human Services (DHHS). (1995). Trends in Indian Health. Washington, DC: Indian Health Services.

U.S. Bureau of the Census. (1991). General population characteristics: 1990 census of population (American Indian and Alaskan Native). Washington, DC: U. S. GPO.

Villarruel, A., \& de Montellano, B. (1992). Culture and pain: A Mesoamerican perspective. Advances in Nursing Science 15(1), 21-32.

Weaver, $H$. (in press). The challenges of research in Native American communities: Incorporating principles of cultural competence. Joumal of Social Services Research.

Weaver, H. N. \& Wodarski, J. S. (in press). Cultural issues in crisis intervention: Guidelines for culturally competent practice. Family Therapy.

Williams, E. E. \& Ellison, F. (1996). Culturally informed social work practice with American Indian clients: Guidelines for non-Indian social workers. Social Work, 41(2), 147-151. 
Wilson, J., Thomann, N., \& Gish, C. (1993). Minority women:

Dimensions in health (U.S. DHHS Region 8 Publication). Greenwood Village, CO: Bachman.

Woodward, G., \& Edouard, L. (1992). Reaching out: A community initiative for disadvantaged pregnant women. Canadian Journal of Public Health. 83(3), 188-190.

Zambrana, R. E., \& Ellis, S. K. (1995). Contemporary research issues in Hispanic/Latino women's health. In D. L. Adams (Ed.), Health issues of women of color. A cultural diversity perspective (pp. 42-70). Thousand Oaks: Sage.

Zimmerman, M. A., Ramirez, J., Washienko, K. M., Walter, B., \& Dyer, S. (1995). Enculturation hypothesis: Exploring direct and protective effects among Native American youth. In H. I. McCubbin, E. A. Thompson, A. I. Thompson, \& J. E. Fromer (Eds)., Resiliency in ethnic minority families, Native and immigrant American families Vol I (pp. 199-224). The University of Wisconsin System: Madison. 
APPENDDX A

RESEARCH APPROVALS

Portland State University

Warm Springs Tribe 


\section{Portland State University}

P.O. Box 751, Pordand, OR 97207-0751

\section{Research and Sponsored Projects}

DATE: $\quad$ March 11, 1996

TO: $\quad$ Claudia Long

FROM: fo Laurie Skokan, Chair, HSRRC, 1995-96

RE: $\quad$ HSRRC Waived Review of Your Application tutled " Kural Uregon Native American Prenatal Project"

Your proposal is exempt from further HSRRC review, and you may proceed with the study.

Even with the exemption above, it was necessary by University policy for you to notify this Committee of the Proposed research and we appreciate your timely attention to this matter. If you make changes in your research protocol, the Committee must be notified. This approval is valid for one year from date of issue. 
Ms. Claudia Long

15542 SW Donna Ct.

Beaverton, or 17707

Dear Claudia;

I have reviewed your proposal to conduct a focus group, research project among 35 - 55 years of age to identify barriers they may have experienced in obtaining prenatal care. After reviewing the proposal it is my decision to grant you permission to conduct the research with the limitation that the confederated Tribes of will not be able to provide you with any staff support to assist you in conducting the project. Additionally I would appreciate being informed how and when you propose to initiate the project.

As I discussed with you on the phone, I will be talking with Mr. - Service Unit Director for the Indian Health service clinic about your proposal and if there are ways in which they can be of assistance to you.

If I can provide you with any further information regarding this matter, please contact me.

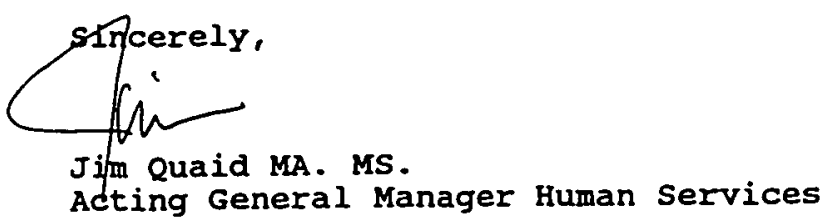


APPENDIX B

CONSENT FORM 

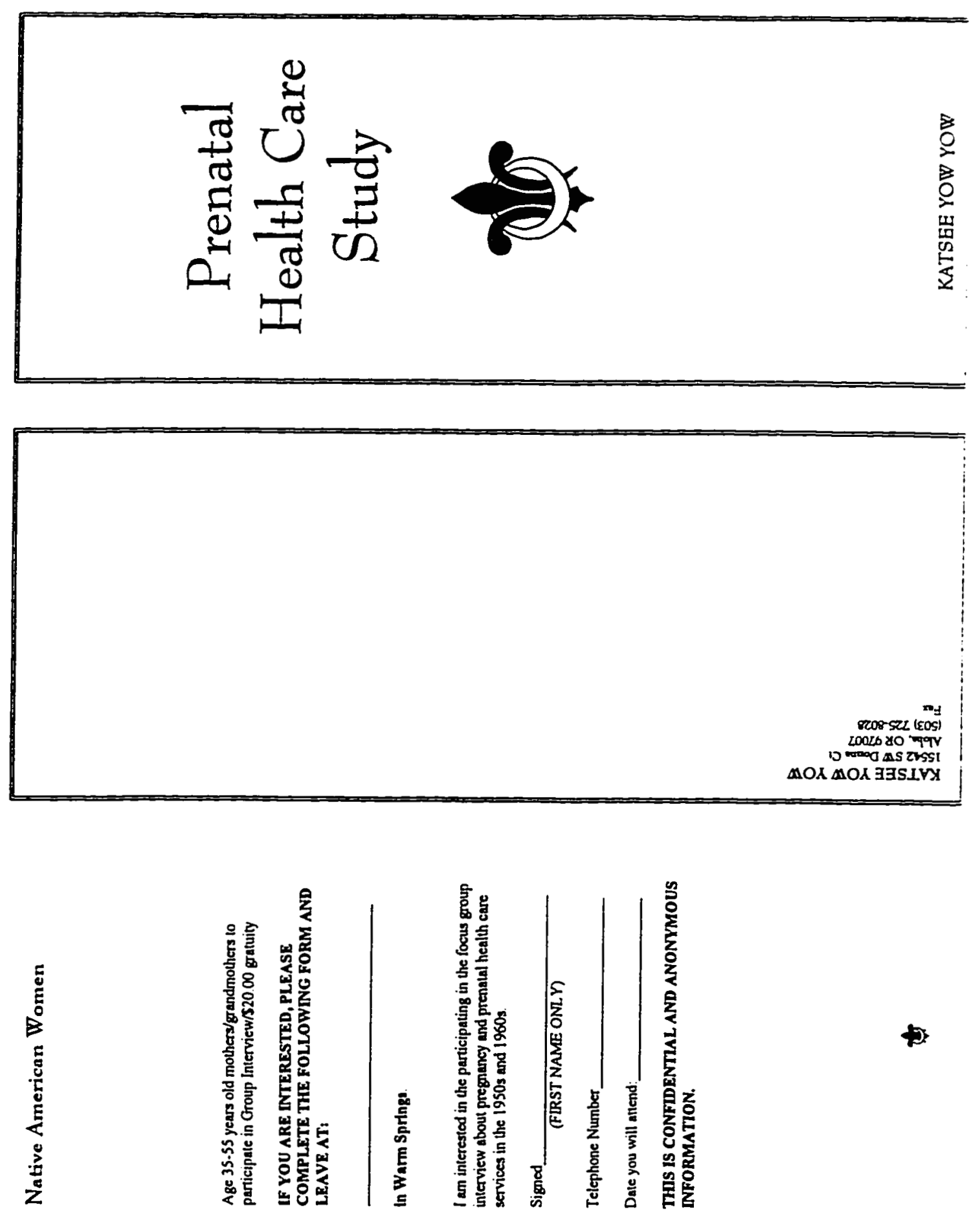

2 

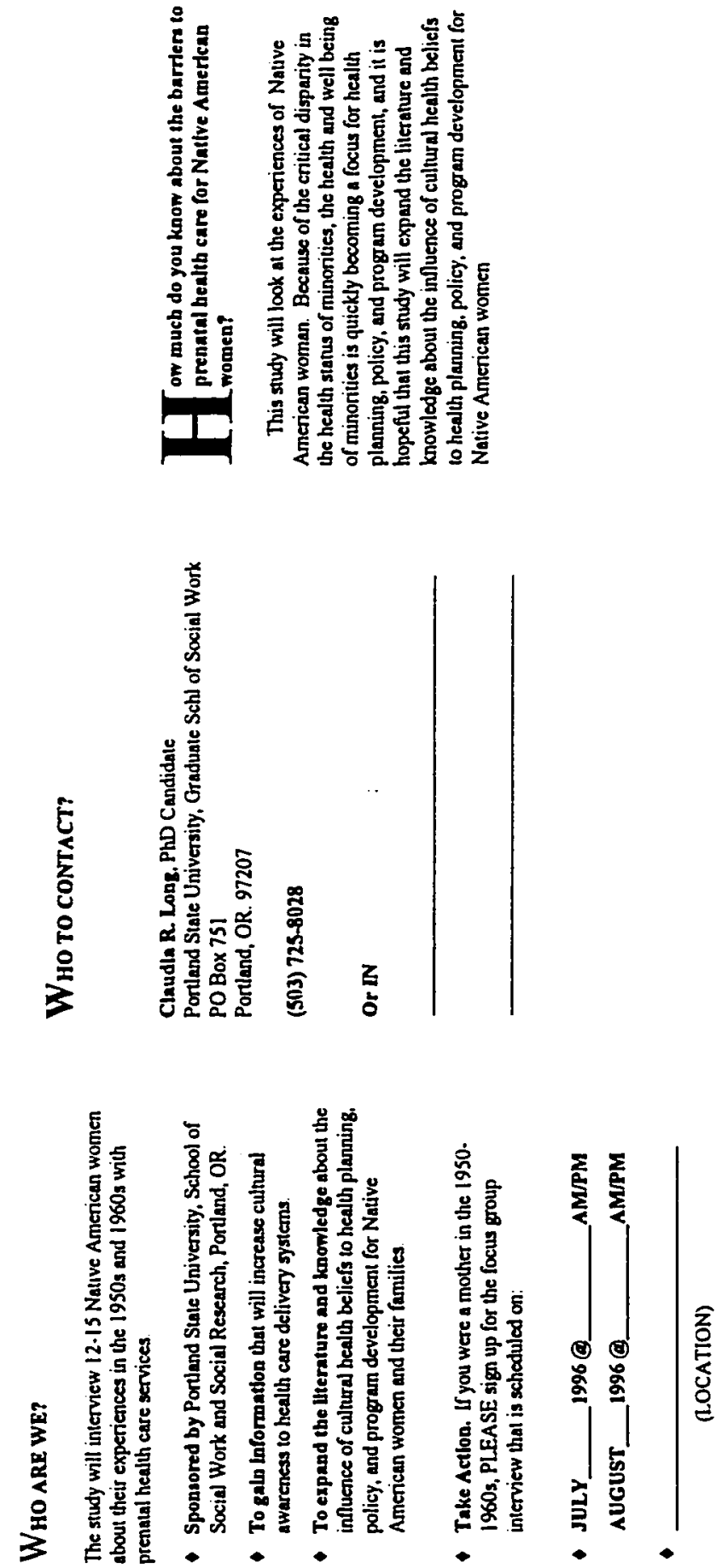
APPENDIX C: INSTRUMENTS

Profile Questionnaire

ECR Instrument

Focus Group Interview Questions 
NATIVE AMERICAN WOMEN'S PREGNANCYICHILDBIRTH STUDY QUESTIONNAIRE

As a participant in the Native American Women's Intergenerational Transmission of

Pregnancy/Childbirth information study, please complete the following questionnaire. All information will remain confidential and anonymous.

YOUR FIRST NAME:

(First name only, PLEASE)

DATE:

MARITAL STATUS: (please check one)

Married Divorced Never Married Separated Widowed

TRIBAL AFFILIATION:

LANGUAGE(S) spoken (OTHER THAN ENGLISH)

CULTURAL ACTIVITIES that you have participated in the last year (such as pow wows, Sweat Lodge, naming ceremony, and so on):

RANGE OF YEARLY FAMILY INCOME: (please check one) Under $\$ 10,000$ $\$ 10,000-25,000$ $\$ 25,000-40,000$ over $\$ 40,000$ 
Page 2 NATIVE AMERICAN WOMEN'S PIC STUDY.

LAST GRADE COMPLETED: (please check one)

Under 8th grade

8-11th grade

12th grade or over

ATTENDED (Please indicate number of years completed)

High School College Business School Vocational Other

CHILD(REN)'S First Name and Age at last birthday:

GRANDCHILD(REN)'S First Name and Age at last birthday: 


\section{Page 3 NATIVE AMERICAN WOMEN'S PIC STUDY}

PLEASE IDENFITY reason for living off-reservation, at what age, and number of years living off-reservation.

\section{LIVING OFF-RESERVATION}

REASONS FOR AGE (at move)l NUMBER OF YEARS MOVE

\begin{tabular}{|c|c|c|c|c|}
\hline Boarding School & $\theta$ & -1year & +1year & +3 years \\
\hline Relocation Program & I & -1year & +1year & +3 years \\
\hline Job & I & -1year & +1year & +3 years \\
\hline Training \&/or Education & 1 & -1year & +1year & +3years \\
\hline /Family (Moved) & 1 & -1year & +1year & +3years \\
\hline "Other Reason: & I & -1year & +1year & +3 years \\
\hline
\end{tabular}

("PLEASE SPECIFY "Other reason" for living off-reservation)

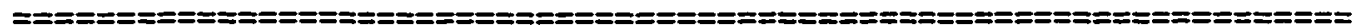

OTHER CONCERNS/SUGGESTIONS THAT YOU HAVE ABOUT PREMATAL HEALTH CARE FOR YOUNG NATIVE AMERICAN WOMEN

GRP C:

THANK YOU for your cooperation in participating in the Native American Women's Pregnancy and Childbirth Study. Please sign, first name only. Thank you, Claudia Long, PhD Candidate at Portland State University, Regional Research Institute, Box 751, Portland, Oregon 97207. (208) 843-7375 or (208) 798-8864. 
ETHNIC, CULTURE, AND RELIGION/SPIRITUALITY QUESTIONNAIRE

First Name:

Date:
Family ID:

Interview: $\longdiv { 2 3 4 }$

1. How do you feel about your ethnic or cultural background? (Circle one.)

$\begin{array}{lll}\text { It's not an } & \text { Ashamed } & \text { I don't } \\ \text { issue forme. } & \text { like it. } & \text { It's OK. }\end{array}$

$\begin{array}{lllll}0 & 1 & 2 & 3 & 4\end{array}$

2. To what degree does your ethnic background work against you? (Circle one.)

$\begin{array}{ccccc}\text { It's not an } & \text { Not at } & \text { Hardly } & \text { Some } & \text { A lor } \\ \text { issue for me. } & \text { all } & 1 & & \\ 0 & 1 & 2 & 3 & 4 .\end{array}$

3. To what degree does your ethnic background help or work for you? (Circle one.)

$\begin{array}{lcccc}\text { It's not an } & \text { Not at } & \text { Hardly } & \text { Some } & \text { A lot } \\ \text { issue for me. } & \text { all } & 1 & 2 & 5\end{array}$

4. How do you feel about your religious/spiritual identity? (Circle one.)

It's not an issue for me.

Ashamed
I don't like it.

2
It's OK. Proud

34

5. To what degree does your religious/spiritual identiry work against you? (Circle one.)

$\begin{array}{lcccc}\text { It's not an } & \text { Not at } & \text { Hardiy } & \text { Some } & \text { A lot } \\ \text { issue for me. } & \text { all } & & & \\ 0 & 1 & 2 & 3 & 4\end{array}$

6. To what degree does your religious/spiritual identity help or work for you? (Circle one.)

It's not 10 issue for me.

0

Not at Hardly Some A lot
all

1
3

4 
7. Do you speak more than one language? (Circle one.) 0 . No 1 . Yes If you answered 'NO', circle ' $O$ ' for questions 72 and $7 \mathrm{~b}$, and go on to question 8.

If you answered "YES":

What is your first language?

What is your second language?

72. To what degree is being bi-lingual helpful to you? (Circle onc.)

$\begin{array}{ccccc}\text { Not Applicable } & \text { Not at all } & \text { Hardly } & \text { Some } & \text { A lot } \\ 0 & 1 & 2 & 3 & 4\end{array}$

7b. To what degree does being bi-lingual work against you? (Circle one.)

$\begin{array}{ccccc}\text { Not Applicable } & \text { Not at all } & \text { Hardly } & \text { Some } & \text { A lot } \\ 0 & 1 & 2 & 3\end{array}$

8. Do you participate in community cultural, ethnic, or religious/spiritual activities? (Powwows. Cinco de Mayo ...)? (Circle one number.)

4 0. No, I don't know of any.

1. No, I know of them but I don't go.

2. Yes. I know of them but only sometimes participate.

3. Yes, I participate regularly.

81. Please list any you have knowledge of currently:

9. Do you make use of community cultural, ethnic, or religious/spiritual resources or helpers (NARA. Priests, ministers...)? (Circle one number.)

0. No, I don't know of any.

1. No, 1 know of them but don't use them.

2. Yes, I know of them but only sometimes use them.

3. Yes, I use them as needed. 
Focus GRoup intexulew

TABLE 2- ${ }^{-}$-

\begin{tabular}{|c|c|c|}
\hline RESEARCH OUESTIONS & METHOO OF INQUIRY & RESEARCH AIM \\
\hline $\begin{array}{l}\text { Demographic descrolor (eg., first name. age. } \\
\text { mantal status): tribal aflitiation: socioeconomic } \\
\text { information (eg. education. income): child(ren)'s age: } \\
\text { moved off-reservation (reason, age, length of time). }\end{array}$ & Questoonnare & $\begin{array}{l}\text { To gather descriptre data from key } \\
\text { participants to provide an accurate } \\
\text { sense of who is participating. }\end{array}$ \\
\hline $\begin{array}{l}\text { 1. Thinking back when you were pregnant and had } \\
\text { your first baby. whal comes to ming? Think of how } \\
\text { is now different. } \\
\text { Probes: Was if easiermarder than to is now in terms } \\
\text { of beliets and practices. }\end{array}$ & Focus Group Interview & $\begin{array}{l}\text { 1. Introduction and describes beliets } \\
\text { and practices of pregnancy and } \\
\text { childbirth among women; now/hen }\end{array}$ \\
\hline $\begin{array}{l}\text { 2. What are some of the ways in which you } \\
\text { gained miomation about pregnancy and having } \\
\text { babies? } \\
\text { Probes: Sweat Lodge. Mothers, grandmothers. } \\
\text { bmity, heath care providers. reading materiats. }\end{array}$ & Foeus Group Interview & $\begin{array}{l}\text { 2. Describes the dynamics of heath } \\
\text { betiefs transmission among women. } x \text {. } \\
\text { the past. }\end{array}$ \\
\hline $\begin{array}{l}\text { 3. What are the ways in which you share } \\
\text { nformation whin your chidgrentiamily about pregnancy } \\
\text { and having babies? } \\
\text { Probes: Cukural ways; contemporary ways. }\end{array}$ & Focus Group interview & $\begin{array}{l}\text { 3. Describes the dynamics of heath } \\
\text { beliets transmission among women. in } \\
\text { the past. }\end{array}$ \\
\hline $\begin{array}{l}\text { 4. What are the differences between the ways n } \\
\text { which young mothers loday kam about pregnancy } \\
\text { and having babies and the ways mothers leamed } \\
\text { about p.a.cb. When you were pregnant and having } \\
\text { babies? Can you think of ways lo make B better } \\
\text { Probes: Sweat Lodge. grandparents, prenatal care. } \\
\text { PHN: Suggestions to make things better. }\end{array}$ & Focus Group Intervew & $\begin{array}{l}\text { 4 Wentifies ditferences among women. } \\
\text { betwreen now and then. in order to } \\
\text { understand prenatal care utification } \\
\text { practices. Wentifies suggestions br } \\
\text { improvement. }\end{array}$ \\
\hline 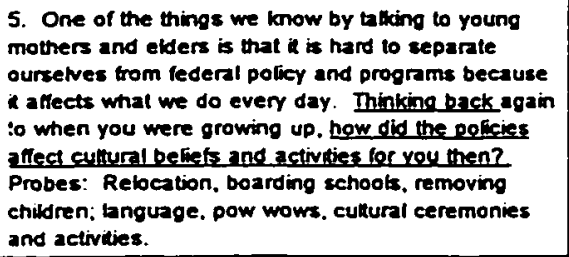 & Focus Group Interview & $\begin{array}{l}\text { 5. Hentifies impact of past } \\
\text { policy/programs on the cuthural beliets } \\
\text { and activities. }\end{array}$ \\
\hline $\begin{array}{l}\text { 6. Thinking back to when you were growing up. unth } \\
\text { you were pregnant. ean you deseribe ware of coping } \\
\text { that were used by you and your family in dealing with } \\
\text { tedernl assimibtion poticies? } \\
\text { Probes: Resiliency of extended family. orat history. } \\
\text { wisdom of elders. going underground; Cthers: } \\
\text { substance use. violence (spousal and so on). }\end{array}$ & Focus Group Interview & $\begin{array}{l}\text { 6. Describes coping mechaniams and } \\
\text { restivency strategies used in the past. }\end{array}$ \\
\hline $\begin{array}{l}\text { 7. Can a theory be developed to explain or etanty } \\
\text { the meaning of preonancy and endobinth and } \\
\text { vanpbles that serve to tacditate or impede_access } 10 \\
\text { erenatal eare? }\end{array}$ & $\begin{array}{l}\text { Grounded Theory } \\
\text { Analysis }\end{array}$ & 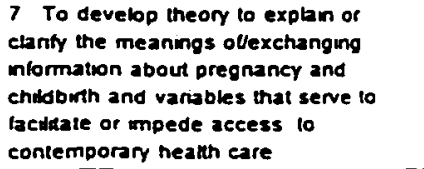 \\
\hline
\end{tabular}


APPENDIX D:

AUDIT DOCUMENTATION 


\section{Credibility Verification: External Audit}

It is my (Julie simpson) understanding that by signing this document I attest to have reviewed and collaborated with Claudia $R$. Long from a sampling of the interview text, themes, codes, and notes that emerged into grounded theory. This audit was recorded as part of the dissertation entitled "Grandmothers" laughing: Intergenerational transmission of cultural health beliefs among Native American women." This was accomplished by reading the original transcript of both taped interviews and the codes, themes, and grounded theory that emerged that was collected and interpreted by the researcher.

Text from both focus groups were sampled as well as notes taken from individual interviews. The audit was based upon deliberation with the researcher about emerging themes that had been clarified and negotiated with participants in individual follow-up interviews following each focus group and not from researcher bias.

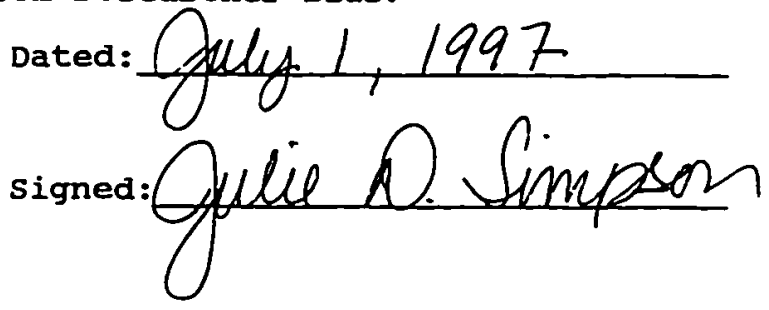




\section{Credibility Verification: Peer Debriefing}

It is my (Bonnie Ewing) understanding that by signing this verification, I will attest to have reviewed and collaborated with Claudia $R$. Long in ongoing consultation by offering feedback throughout the study. The debriefing activities were part of the dissertation study entitled "Grandmothers' laughing: Intergenerational transmission of cultural health beliefs among Native American women." For purposes of establishing credibility of the findings, the researcher's biases were probed, meanings explored, and the basis of interpretations were clarified within these debriefing activities.

The major aim of these debriefing activities were utilized to provide an external check on the inquiry process. Emergent themes provided for an on-going process that resulted in confirmation and negotiation with participants in the second session and by individual followup interviews.

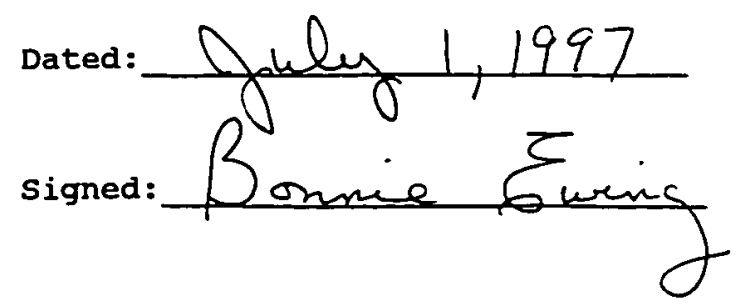




\section{Dependability and confinmability Verification:}

\section{External Audit}

It is my (Connie Evans) understanding that by signing this External Audit Verification that I attest to have reviewed and collaborated with claudia $R$. Long about the dependability and confirmability in the dissertation entitled "Grandmothers' laughing: Intergenerational transmission of culturall health beliefs." The dependability of the researcher (as the instrument of the study) was examined in this audit by review of the (1) process and (2) the data, (3) findings, (4) interpretations, and (5) analysis products within the audit trail. This included field notes, findings, final report, connections to existing literature, relationships, interpretations, preliminary and revised schedules, questionnaires.

I also attest to the confirmability that findings were generated by participants and not by biases and motivations of the researcher. This was accomplished by examination of logs that tracked activities, reflections, and emergent hypothesis.

$$
\begin{aligned}
& \text { Dated } 7-9-97 \\
& \text { signed ionsice Evans }
\end{aligned}
$$

